This is the final peer-reviewed accepted manuscript of:

Giuseppina Montante, Alessandro Paglianti, Gas hold-up distribution and mixing time in gas-liquid stirred tanks, Chemical Engineering Journal, Volume 279, 2015, Pages 648-658, ISSN 1385-8947

The final published version is available online at:

https://doi.org/10.1016/i.cej.2015.05.058

Rights / License:

The terms and conditions for the reuse of this version of the manuscript are specified in the publishing policy. For all terms of use and more information see the publisher's website.

This item was downloaded from IRIS Università di Bologna (https://cris.unibo.it/)

When citing, please refer to the published version. 


\title{
Gas Hold-up Distribution and Mixing Time in Gas-Liquid Stirred Tanks
}

Giuseppina Montante ${ }^{\mathrm{a}, \S}$, Alessandro Paglianti ${ }^{\mathrm{b}}$

${ }^{a}$ Department of Industrial Chemistry, Università di Bologna, via Terracini 28, 40131 Bologna, Italy. ${ }^{b}$ Department of Civil, Chemical, Environmental and Materials Engineering, Università di Bologna, via Terracini 28, 40131 Bologna, Italy.

\begin{abstract}
In this work, the gas-liquid dispersion in a stirred tank equipped with different impellers is investigated by Electrical Resistance Tomography (ERT). The main goal of the study is to provide detailed information on the spatial distribution of the gas phase and on the effect of bubbles on the liquid homogenization dynamics. The analysis is carried out under variable gas flow rates and impeller speeds, thus covering different regimes of gas-impeller interaction, as obtained by Rushton Turbines, Pitched Blade Turbines pumping upwards and Lightnin A310. The experimental technique allows us to overcome the typical limitations of optical methods and to gain insight into the complex behaviour of sparged stirred tanks without restriction on the upper value of overall gas hold-up, that is of great interest for several chemical and biochemical processes. Besides, the experimental data can be adopted as a benchmark for advanced modelling techniques based on CFD methods, whose scant validation is often due to limited information on the local dispersion features. The analysis of experimental results allows us to suggest simple correlations for the prediction of the prevailing flow regime based on the dimensionless Froude and Flow numbers. Finally, the definition of a modified Peclet number is also suggested, as a simple parameter for the interpretation of both the gas hold-up distribution and the dimensionless mixing time.
\end{abstract}

Keywords: gas-liquid; stirred vessel; Electrical Resistance Tomography; mixing time; gas hold-up distribution; mixing.

${ }^{\S}$ Corresponding author: Tel: +39 051 2090406; Fax: +39 0516347788 ;

E-mail: giuseppina.montante@ unibo.it (Giuseppina Montante) 


\section{INTRODUCTION}

The gas dispersion in stirred tanks is a widespread operation in the chemical and biochemical industry, whose effective accomplishment importantly affects mixing, heat and mass transfer and ultimately the chemical/biochemical reactions involved in the overall industrial processes. Several aspects of the complex hydrodynamics of the two-phase turbulent flow in stirred gas-liquid contactors have been investigated in the past decades [1], moving over the years from the overall characteristics of systems of different geometries under variable operation conditions (such as power consumption [2,3], overall gas hold-up [2-5], gas dispersion regimes [4,5], liquid mixing time under gassed conditions [2,3,6,7]) to, more recently, local variables based on advanced techniques (liquid and gas velocity fields [8-10], bubbles size distribution [11-12], local gas hold-up [13-17]).

The development of experimental techniques enabling the collection of local velocity, size and concentration distribution of the dispersed phase, together with the relevant variable of the continuous liquid phase, has provided a significant contribution to the enhancement of both the geometrical design and the modelling of gas-liquid stirred tanks [8,11,18-19].

Among the numerous aspects which still deserve further investigation, the gas hold-up distribution and the liquid mixing time in sparged stirred tanks are those considered in this work. The local determination of the gas volume fraction in stirred tanks has been mainly based either on optical or conductivity probes and more recently on the application of Electrical Resistance Tomography (ERT). One of the first contributions to the determination of the local void fraction in aerated stirred tanks is due to Bombac et al. [13], who based their measurements on a point-wise resistivity probe providing novel maps of gas distribution under different gassed regimes. Recently, Kong et al. [15] have applied a $\gamma$-CT scan method to the analysis of the impeller region of a standard geometry gassed stirred tank finding consistent results with those published by Bombac et al. [13] and adding further insight into the effect of operating conditions on the local gas distribution. Among others, the local gas hold-up was also determined by an impedance method by Paglianti and Pintus [21] and by a novel optical technique by Busciglio et al. [14]. A recent contribution of Lee and Dudukovic [16] has shown the capability of a novel technique based on the analysis of optical fiber probe data to identify the flow regime transition from the flooding to the loading regimes in a standard geometry stirred tank. The suitability of ERT for the investigation of gas-liquid stirred tanks has been demonstrated among the first by Wang et al. [22] and it has been lately applied also to three phase systems [23]. A recent review on the application of ERT to chemical engineering apparatuses, including gas-liquid systems and stirred tanks has been performed by Sharifi and Young [24]. Overall, the local characterization of the gas distribution in sparged stirred tanks with high gas hold- 
up by non-intrusive methods has been performed in a limited number of cases. As for the ERT investigations, the results have been mainly presented as qualitative tomograms, rather than by quantitative methods. Further experimental information on different impellers and deeper insight into the system characteristics, based on suitable parameter estimations, is expected to provide a useful contribution to improve design and modelling of aerated reactors and bioreactor.

As for the liquid mixing time in gassed stirred tanks, depending on the relative importance of the energy transfer from the gas phase and the power drawn from the impeller, different effects of aeration can be observed [25]. For known stirred tank configurations, the usual correlation suitable for ungassed systems can be adopted, by accounting for the real power consumption [2] and specific methods have been developed [7], while for unconventional geometries and multiple impeller systems, modifications to the standard correlation are required even in ungassed systems [26], and specific investigation are necessary for the identification of reliable correlations based on parameter fitting procedures [17]. The successful prediction of mixing time in gas-liquid stirred tanks by advanced modelling technique has been recently reported among others by Zhang et al. [27]. Nevertheless, the capability of the current modelling techniques in the prediction of all the complex features of gas-liquid systems, including the bubble size distribution and the impeller-bubble interaction regimes, which in turn affect the liquid flow patterns and the macro-mixing characteristics, still requires extensive validation. On the experimental side, the techniques based on conductivity probes for single phase systems require appropriate modifications in aerated conditions [28], the optical methods are limited to very low gas hold-up, while in principle the application of ERT does not suffer of any limitation. Indeed, it has been successful adopted for the dynamic characterization of single-phase stirred tanks [29-31], as well as for two-phase systems [22, 32, 33], but, at the best of our knowledge, comprehensive investigations on the mixing time of gas-liquid stirred tanks based on ERT are not available to date.

Previous investigations on gas-liquid systems have demonstrated the advantages of moving from the traditional configurations, based on the adoption of radial turbines, to down-pumping or uppumping impellers $[34,35]$. Depending on the impeller type, significant reduction of power consumption and suppression of mechanical torque instabilities may be achieved.

Notwithstanding these characteristics, which might results in significant improvements on the industrial operations, detailed experimental results and suitable evaluation parameters for the comparison of the local gas dispersion quality with the different impellers are not available. Limited results have been presented so far on gas-liquid systems stirred with radial impellers [22, 36], the radial and down-pumping impellers have been compared in one case only [37], while the local gas distribution for the up-pumping mode has never been presented. Moreover, the results have been 
mainly discussed based on ERT images observation only, while a quantitative comparison among the different local distributions obtained with various impellers has never been performed.

In this work, the gas hold-up distribution and the liquid mixing time have been measured by ERT in a baffled tank stirred by either the classical Rushton turbine and axial impellers pumping downwards (the Lightnin A130) and upwards (the 6-bladed $45^{\circ}$ Pitched Blade Turbine). Comparative quantification based on local data has been sought. The outcomes of this investigation provide novel local data suitable for complex model validation and can be also directly adopted for obtaining practical guidelines for the operation of aerated stirred tanks.

\section{MATERIAL AND METHODS}

\subsection{The gas-liquid stirred tank}

The investigated apparatus was a lab scale baffled stirred tank, whose settings follow widely adopted geometrical proportions among the relevant dimensions. It consisted of a cylindrical, flat bottomed vessel of diameter, $\mathrm{T}$, equal to $0.232 \mathrm{~m}$ and height, $\mathrm{H}$, equal to $0.28 \mathrm{~m}$, equipped with four equally-spaced baffles of width equal to T/10. In order to evaluate the gas dispersion features under radial, axial and mixed prevailing flow fields, a Rushton turbine (RT), a Lightnin A310 (A310) and a 6-bladed $45^{\circ}$ Pitched Blade Turbine pumping upwards (PBTU) were adopted. The diameter, D, and the off bottom clearance, $\mathrm{C}$, of each impeller are summarized in Table 1. For gas sparging, a porous membrane fixed on the top of a tube of $8 \mathrm{~mm}$ in diameter placed on the vessel axis at a distance equal to T/4 from the vessel bottom was adopted.

\begin{tabular}{llll}
\hline Impeller type & $\mathrm{D}(\mathrm{m})$ & $\mathrm{D} / \mathrm{T}(-)$ & $\mathrm{C} / \mathrm{T}(-)$ \\
\hline \hline RT & 0.078 & 0.33 & 0.33 \\
\hline PBTU & 0.078 & 0.33 & 0.33 \\
\hline A310 & 0.096 & 0.4 & 0.33
\end{tabular}

Table 1. Size and off-bottom clearance of the agitators.

Air and demineralised water were selected as the gas and the liquid phases, respectively. The addition of a very small amount of sodium chloride to water $(0.07 \mathrm{~g} / \mathrm{L})$ ensured a sufficient conductivity difference between the non conductive gas and the liquid, as required by the ERT technique, while maintaining the same density and viscosity and the coalescing behaviour [38] of demineralised water. The ungassed liquid height, $\mathrm{H}_{\mathrm{L}}$, was always maintained equal to $\mathrm{T}$.

As for the operating conditions, the impeller speed, N, was varied stepwise from 100 to $500 \mathrm{rpm}$ with a step size of $100 \mathrm{rpm}$, and the gas flow rate, $\mathrm{Q}_{\mathrm{G}}$, was varied from $0.5 \mathrm{vvm}$ up to 2 vvm with a 
step size of $0.5 \mathrm{vvm}$. As a result, the measurements covered flooding, loading and fully dispersed conditions [1].

\subsection{The ERT measurement set-up}

The gas hold-up distribution and the mixing time were determined by the measurement system schematically depicted in Figure 1, based on the adoption of the ITS P2000 ERT instrumentation by Industrial Tomography Systems Ltd.

The capability of the different impellers to ensure the complete gas dispersion and the transition between different gas-liquid flow regimes was assessed by measurements on two horizontal planes. They were located one below the impeller $\left(\mathrm{z}_{1}=40 \mathrm{~mm}\right.$ from the vessel bottom, that is $\left.\mathrm{z}_{1} / \mathrm{T}=0.17\right)$ and one above it $\left(\mathrm{z}_{2}=140 \mathrm{~mm}\right.$ from the vessel bottom, that is $\left.\mathrm{z}_{2} / \mathrm{T}=0.6\right)$. Each plane was equipped with 16 equally spaced electrodes, which consisted of squared stainless steel plates of $20 \mathrm{~mm}$ side and $1 \mathrm{~mm}$ thickness fixed to the vessel wall and connected to the Data acquisition system (DAS) by coaxial cables.

\subsubsection{The voltage measurement and the conductivity reconstruction method}

The circular adjacent strategy was employed for the voltage measurement, that is the current was injected by an adjacent electrodes pair at a time and the voltage difference was measured from the remaining pairs of electrodes. The intensity of the injected current was equal to $9 \mathrm{~mA}$ and the frequency was fixed at $9600 \mathrm{~Hz}$.

The procedure was repeated for all pairs of electrodes, thus 104 voltage values were collected. This strategy has been preferred to others, as for instance to the diagonal measurement strategy [39], since it was already shown to lead to accurate measurements also for $3 \mathrm{D}$ off-line reconstructions [40].

The conductivity maps were obtained from the measured voltage by the linearized back projection algorithm, which allows a fast image reconstruction and on-line monitoring. This algorithm has been previously selected both for the analysis of gas-liquid systems (e.g. [37]) and for solid-liquid systems (e.g. [41]), while the advantage of moving to more sophisticated methods is still not fully verified. The reconstructed tomograms consisted of 316 conductivity values per plane, obtained adopting a square mesh of size equal to 20 pixels, corresponding to $11.5 \mathrm{~mm}$. 


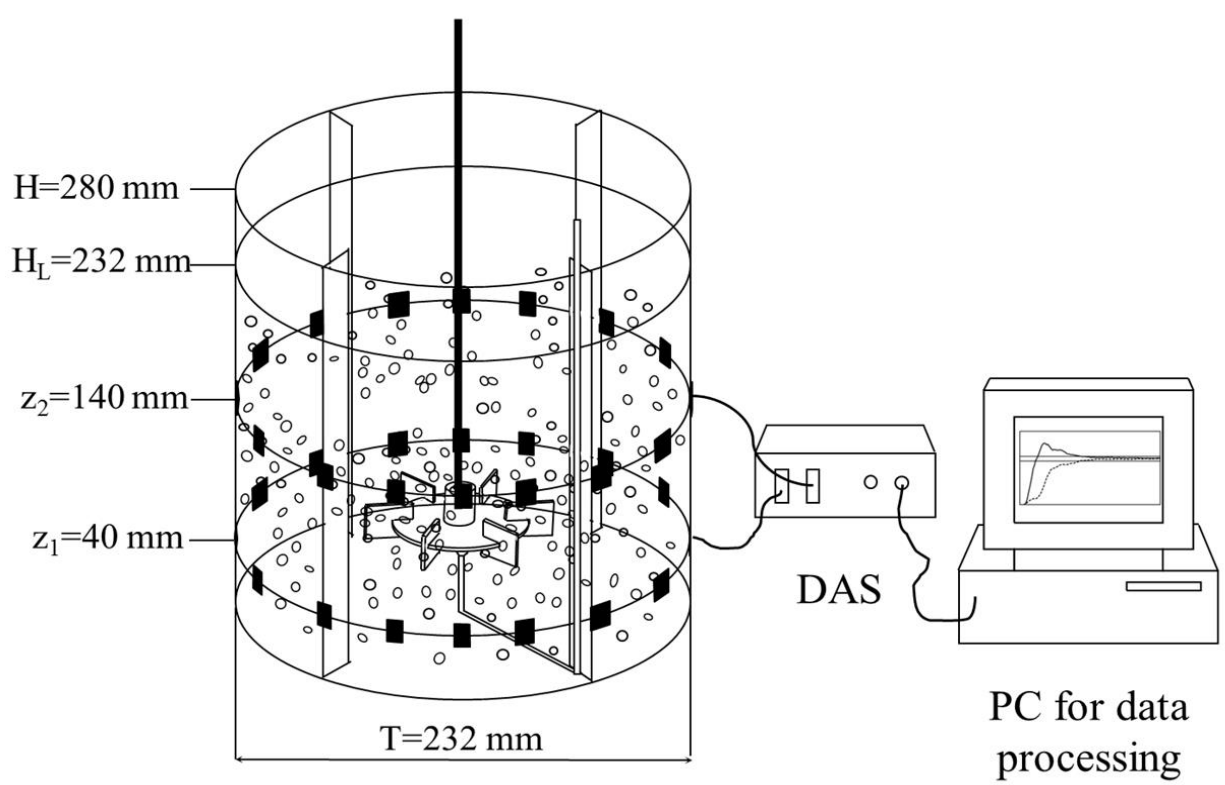

Figure 1. The measurement system.

The gas hold up distribution was measured collecting 600 total instantaneous measurements, at a frequency of 4 frames per second for each experimental condition.

Due to the limited spatial resolution, ERT cannot capture the bubble size distribution [42], but it is able to identify the gas hold-up variations and therefore the different gas flow regimes, which take place in the stirred tank depending on the operating conditions.

\subsubsection{Estimation of the measurement uncertainties}

The statistic independency of the averaged results was verified in advance, by specific tests performed with a variable number of instantaneous samples. The local reproducibility of the mean conductivity values was greater than 99.9\%. Preliminary measurements with water only were performed at the same temperature of the two phase measurements, in order to measure the pure liquid conductivity, that was used as a reference.

The measurement uncertainties are basically due to electronic noise and to liquid temperature variations. As for the latter, the source of uncertainty is associated to any local temperature change between the measurements in ungassed and gassed conditions, since the final tomogram is obtained as the ratio between the gas-liquid mixture conductivity and the corresponding single phase value. The overall experimental error has been estimated comparing two consecutive acquisitions performed with pure liquid. The maximum local difference measured on the mean value over 600 acquisitions was found to be equal to $0.1 \%$. 
In the following, for avoiding misinterpretation of the results, any value of dimensionless mixture conductivity greater than 1 has been set equal to 1 . This correction was actually required for a very limited number of pixels.

\subsubsection{Experimental procedure for the mixing time measurement}

A small amount of saturated $\mathrm{NaCl}$ aqueous solution $(2.5 \mathrm{~mL})$ was added almost instantaneously at $62 \mathrm{~mm}$ from the vessel bottom, through a $2 \mathrm{~mm}$ ID tube located beside the gas sparger and the liquid conductivity was recorded.

From the time evolution of the averaged conductivity on each measurement plane, the time corresponding to the $95 \%$ homogeneity level, $\mathrm{t}_{95}$, was estimated and the maximum of the two values has been considered as the mixing time of the vessel. The experiments were repeated at least three times and the value of the standard deviation of the experimental data decreases at increasing impeller speed, going from the maximum value of $1.5 \mathrm{~s}$ at $\mathrm{N}=100 \mathrm{rpm}$, down to $0.3 \mathrm{~s}$ at $\mathrm{N}=400 \mathrm{rpm}$. The influence of the position of the tracer addition, which is known to affect the mixing time (e.g. [43]) was not specifically investigated; it was expected that its impact on the results should not be more important than that found with other techniques.

\section{RESULTS AND DISCUSSION}

\subsection{The gas hold-up distribution}

The gas-liquid distribution features can be analysed considering the variation of the dimensionless conductivity, $\sigma$, that is the conductivity of the mixture divided by the conductivity of the pure liquid. It is proportional to the liquid hold-up and varies from 0 (pure gas) to 1 (pure liquid). In order to directly consider the gas hold-up distribution instead, the parameter $\varepsilon$, that is defined as $100 \times(1$ $\sigma$ ), is reported in Figure 2, as a function of the product of the gas flow number, Fl, the impeller Reynolds number, Re, and the Froude number, Fr, as originally suggested by Smith [4], who found a linear correlation of several data of gas hold-up collected at different scales mostly in tanks of standard geometry stirred with radial impellers. It is worth to point out that $\varepsilon$ is only proportional to the gas hold-up, but it does not coincide with it. Due to the uncertainties of the correlations for the conversion of conductivity in gas hold-up, the analysis of the collected conductivity values has been preferred, for avoiding any kind of subjectivity in the analysis of the experimental data.

Also, a linear relationship between the local gas hold-up and the sole Fr number has been recently found by Lee and Dudukovic [16]. As can be observed, the results collected in this work with the Rushton turbine and the A310 impeller confirm the linear relationship relevant to the overall hold- 
up estimation performed in the past for stirred tanks equipped with radial impellers. As a difference of the other two impellers, the PBTU results deviate from the linear trend. Clearly, the effect associated to the particular flow pattern of the up-pumping mode is not taken into account by the dimensionless parameters already identified for the radial turbines.

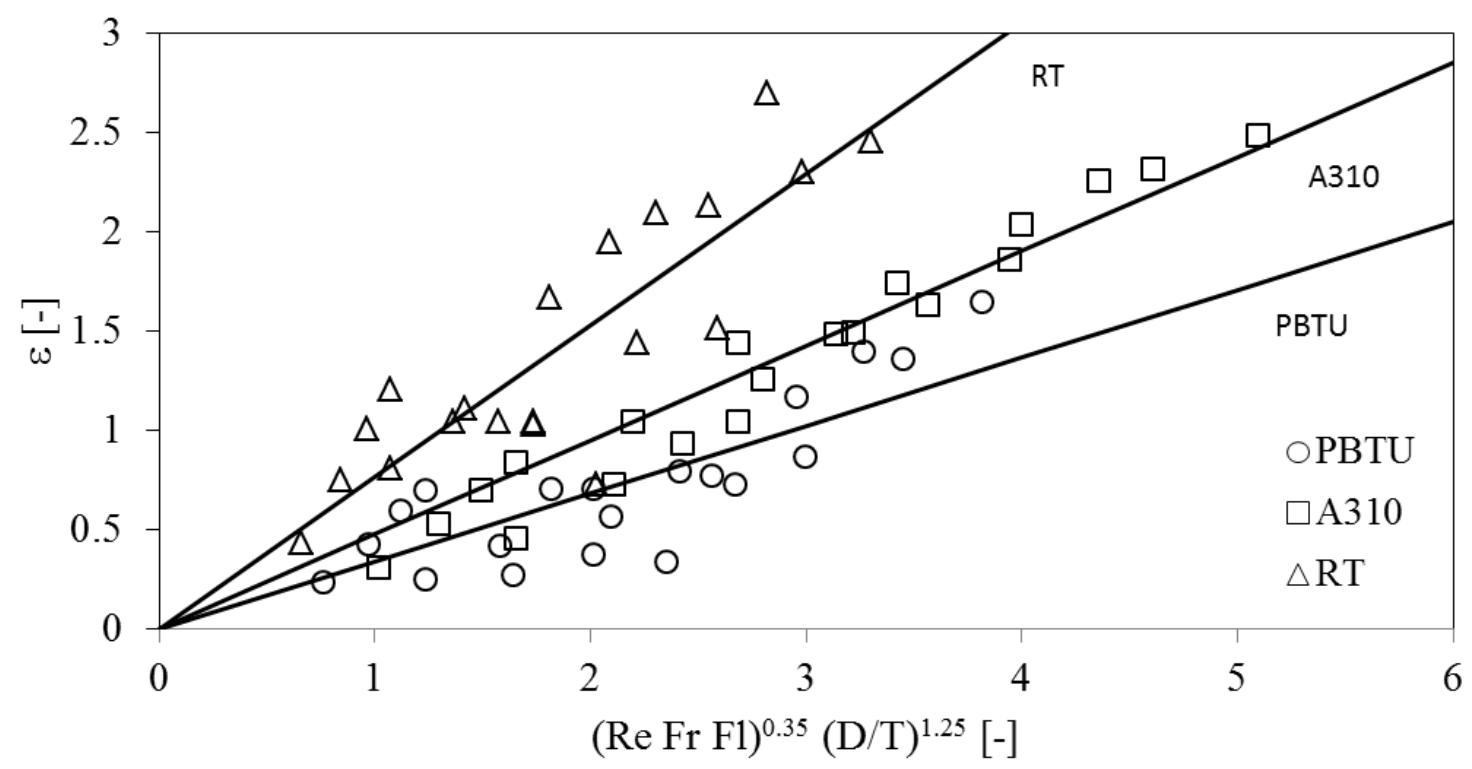

Figure 2. Average $\varepsilon$ measured with different impellers and operating conditions.

The gas-liquid distribution on the two measurement planes, as obtained with the RT at different impeller speeds and gas flow rates, is shown in Figure 3. Among the different combinations of investigated operating conditions, six cases were selected, whose flow regimes was identified on the basis of the flow map firstly proposed by Warmoeskerken and Smith [5]. The results are presented as maps of ensemble averaged dimensionless conductivity, $\sigma$. As can observed, the ERT measurements provide information on the non-homogeneous gas distribution obtained in the flooding regime (Figure $3 \mathrm{a}, \mathrm{b}$ ): the gas hold-up is significant only in the central region of the lower plane, while above the impeller the gas bubbles are mainly confined close to the shaft. The progressive improvement of the gas distribution is apparent at increased impeller speed, moving to the loading regimes (Figure $3 \mathrm{c}, \mathrm{d}, \mathrm{e}$ ) with a different distribution depending on the size of the gas cavities behind the impeller blades, whose configurations were named large 3-3 structure (L33), small 3-3 structure (S33) and vortex clinging (VC) cavities [5,13]. Completely dispersed conditions (Figure 3f) do correspond to good gas homogeneity both below and above the impeller plane. Also, the improvement of the gas dispersion at fixed gas flow rate $\left(\mathrm{Q}_{\mathrm{G}}=2 \mathrm{vvm}\right)$ and increasing impeller speed $(\mathrm{N}=100,300,500 \mathrm{rpm})$ can be appreciated (Figure $3 \mathrm{a}, \mathrm{b}, \mathrm{d})$. The requirement of tangential 
hold-up profiles determination for the appropriate description of the cross-sectional average gas hold-up is confirmed [16]. Overall, the expected gas distribution based on the known regimes of gas-impeller interaction is obtained by the distribution of dimensionless conductivity, which provides in addition quantitative and local information on the gas homogeneity under the various conditions.

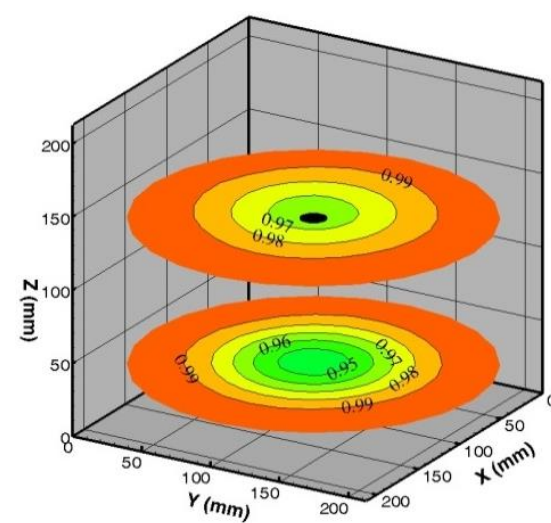

(a)

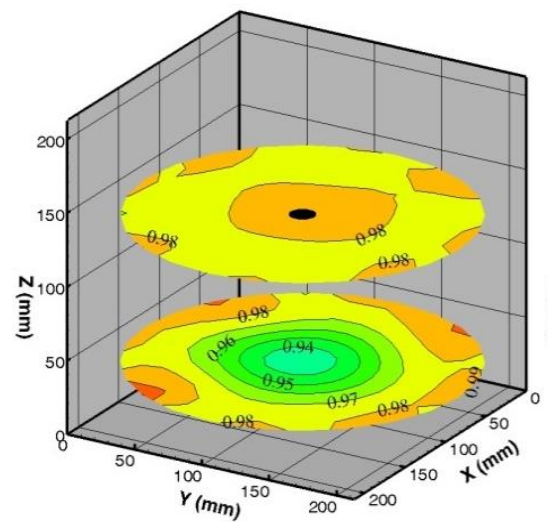

(d)

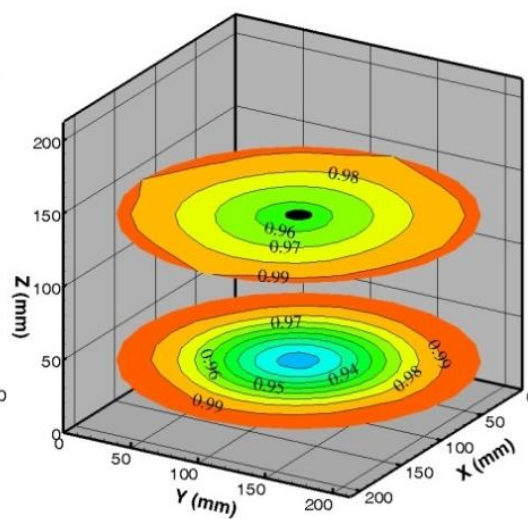

(b)

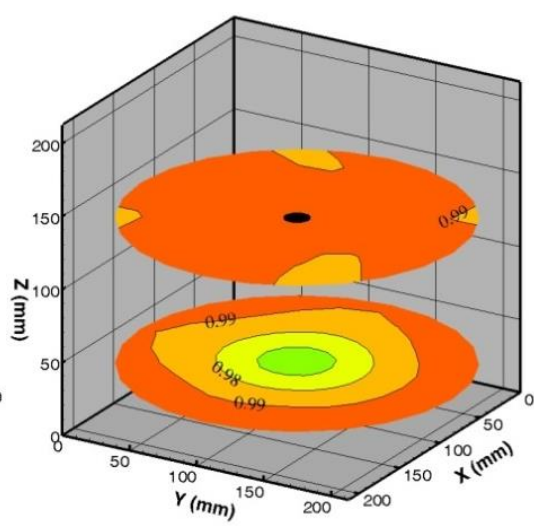

(e)

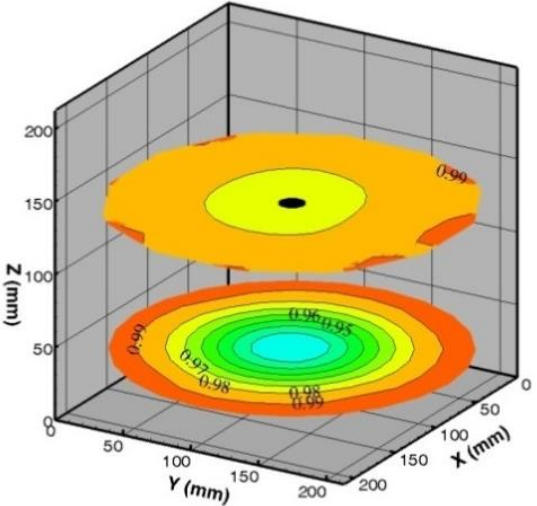

(c)

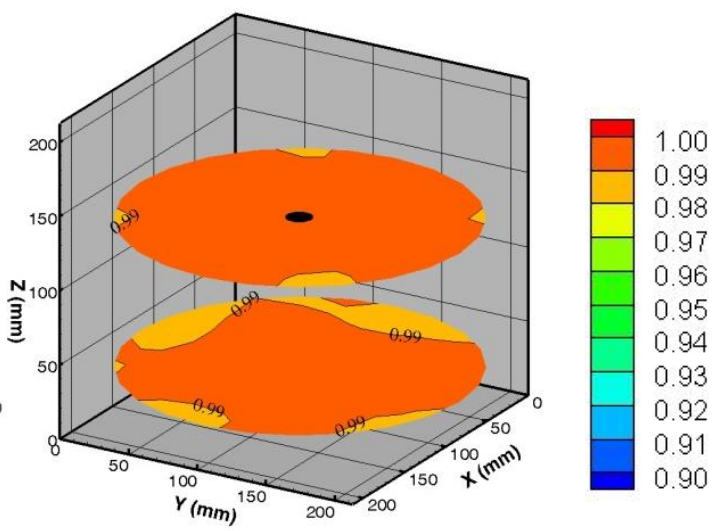

(f)

Figure 3. Dimensionless conductivity, RT. (a) N=100 rpm, $\mathrm{Q}_{\mathrm{G}}=2 \mathrm{vvm}$ (flooding); (b) $\mathrm{N}=300 \mathrm{rpm}$, $\mathrm{Q}_{\mathrm{G}}=2 \mathrm{vvm}$ (flooding); (c) N=300 rpm, $\mathrm{Q}_{\mathrm{G}}=1.5 \mathrm{vvm}(\mathrm{L} 33)$; (d) N=500 rpm, $\mathrm{Q}_{\mathrm{G}}=2 \mathrm{vvm}(\mathrm{S} 33)$; (e) $\mathrm{N}=400 \mathrm{rpm}, \mathrm{Q}_{\mathrm{G}}=0.5 \mathrm{vvm}(\mathrm{VC})$; (f) $\mathrm{N}=500 \mathrm{rpm}, \mathrm{Q}_{\mathrm{G}}=0.5 \mathrm{vvm}$ (completely dispersed).

The experimental data obtained on the two planes can be adopted also for extending the analysis to the impeller plane region.

The 3D reconstruction of the conductivity iso-surfaces for the values of 0.98 and 0.96 is shown in Figure 4. As can be observed, if the impeller is flooded (Figure 4a), vertical structures due to the bubbles' buoyancy take place, which are not disrupted by the impeller action (conductivity isosurface at 0.98). Also, a zone with higher gas hold-up below the impeller (conductivity iso-surface at 0.96 ) is apparent. In the loading conditions, the vertical structures are gradually disrupted moving 
from L33 (Figure 4b) to S33 (Figure 4c) and finally to VC (Figure 4d), while below the impeller a zone of high gas hold-up is still present. For completely dispersed conditions, both the iso-surfaces observed under the previous conditions disappear (Figure 4e). These results allow to clearly identify the significant differences among the flow regimes.

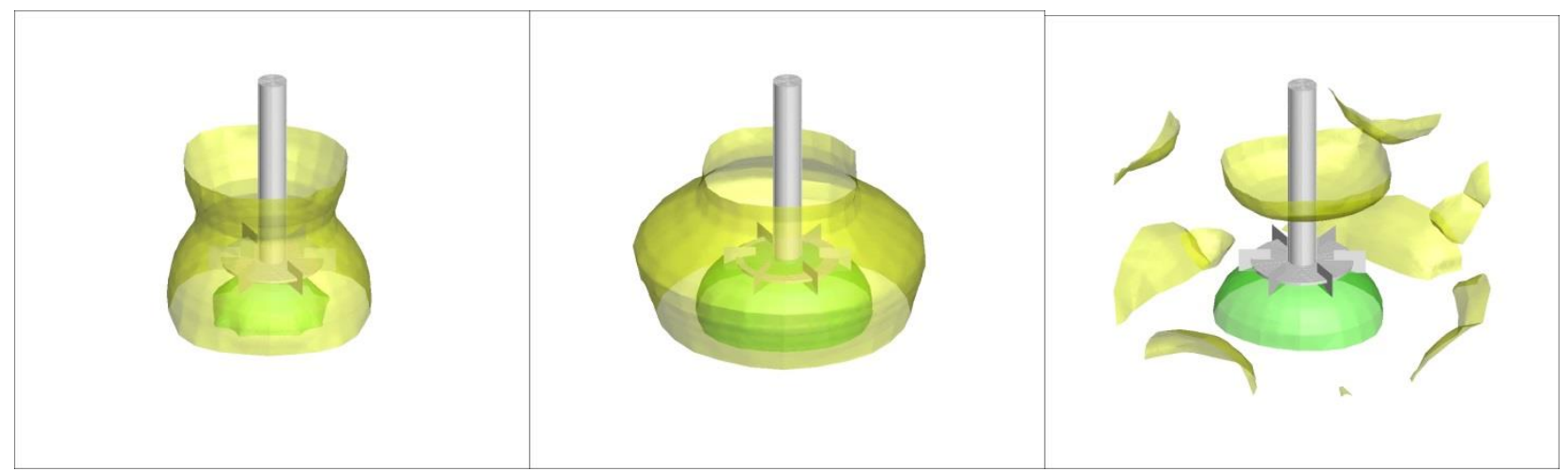

(a)

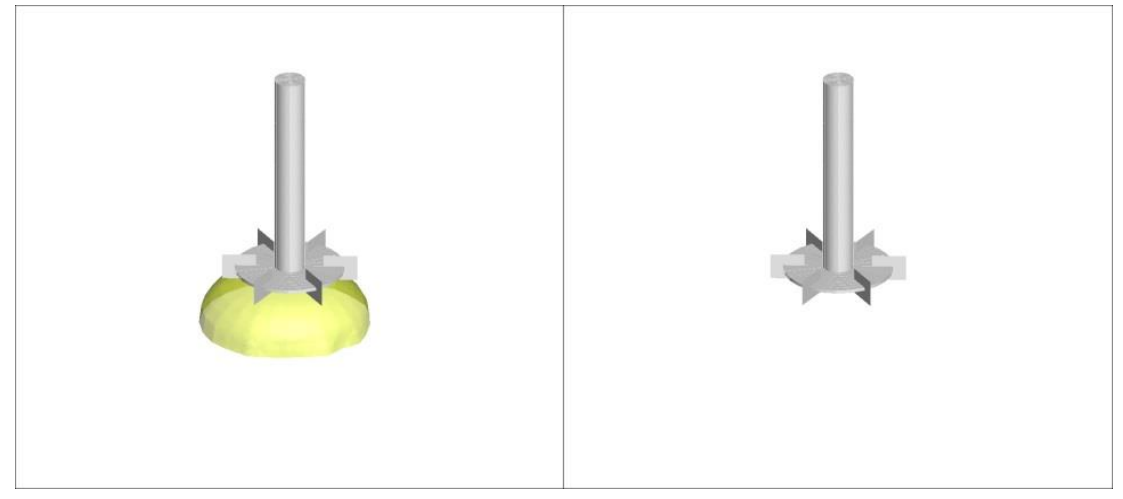

(d) (b)

(e) (c)

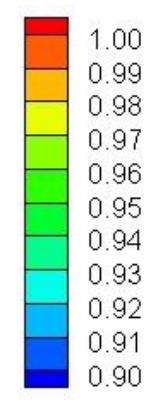

0.90

Figure 4. Iso-surface of dimensionless conductivity at 0.98 and $0.96, \mathrm{RT}$. (a) N=100 rpm, $\mathrm{Q}_{\mathrm{G}}=2$ vvm (flooding); (b) N=300 rpm, $\mathrm{Q}_{\mathrm{G}}=1.5 \mathrm{vvm}$ (L33); (c) N=500 rpm, $\mathrm{Q}_{\mathrm{G}}=2 \mathrm{vvm}$ (S33); (d) N=400 $\mathrm{rpm}, \mathrm{Q}_{\mathrm{G}}=0.5 \mathrm{vvm}(\mathrm{VC}) ;(\mathrm{e}) \mathrm{N}=500 \mathrm{rpm}, \mathrm{Q}_{\mathrm{G}}=0.5 \mathrm{vvm}$ (completely dispersed).

The gas hold-up distributions obtained with the $\mathrm{A} 310$ under fixed gas flow rate $\left(\mathrm{Q}_{\mathrm{G}}=2 \mathrm{vvm}\right)$ and increasing impeller speed are reported in Figure 5. From the visual observation of the gas distribution, the differences obtained increasing the impeller speeds from $100 \mathrm{rpm}$ (Figure 5a) to $300 \mathrm{rpm}$ (Figure 5b) can be observed. Below the impeller, the minimum value of dimensionless conductivity moves from 0.97 to 0.93 . Major differences with respect to the case of radial pumping can be appreciated at the higher impeller speed (Figure $5 \mathrm{c}$ ), particularly on the lower plane, where the progressive increase of the gas hold-up due to the down pumping effect is obtained. Overall, the bubbles are more effectively distributed by the RT than with the A310, as expected. 


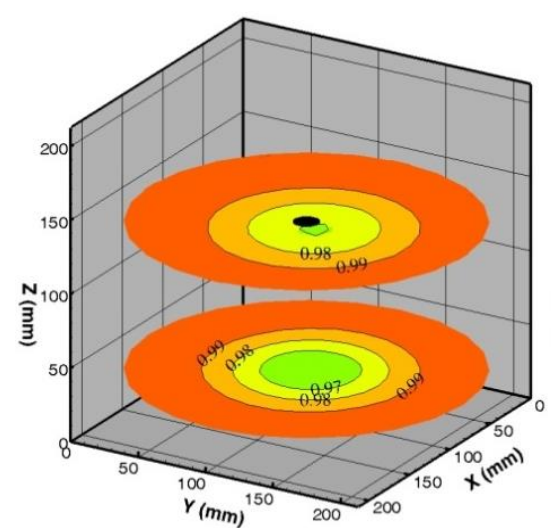

(a)

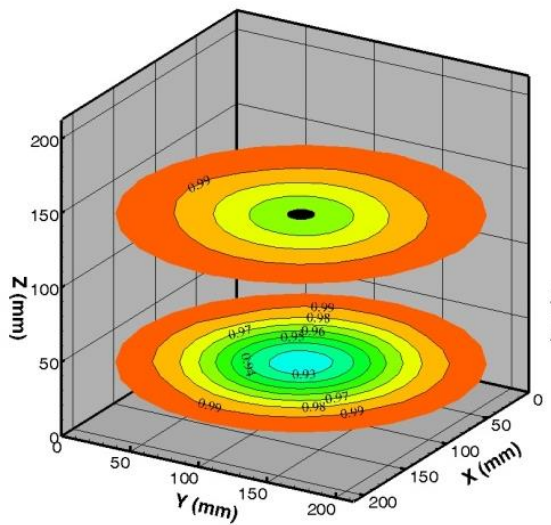

(b)

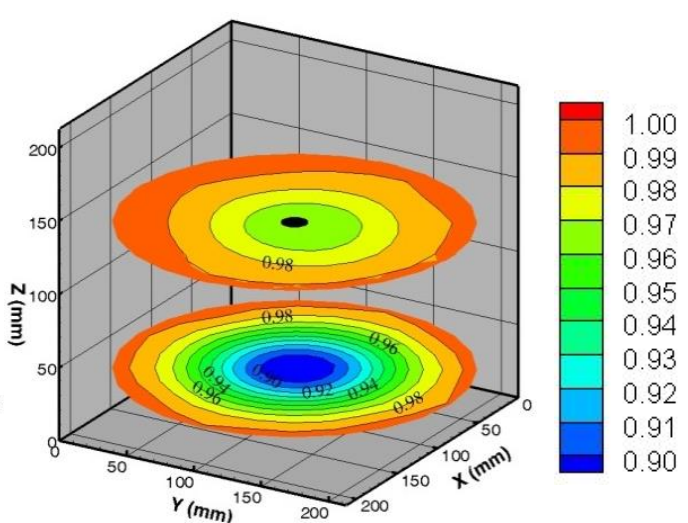

(c)

Figure 5. Dimensionless conductivity, $A 310$ impeller $Q_{G}=2 v v m$. (a) $N=100 \mathrm{rpm}$ (b) N=300 rpm (c) $\mathrm{N}=500 \mathrm{rpm}$.

The results shown in Figure 6 provide the local conductivity values obtained with the PBTU under the same operating conditions of those shown in Figure 5 and they allow to directly compare the gas distribution characteristics of the two impellers.

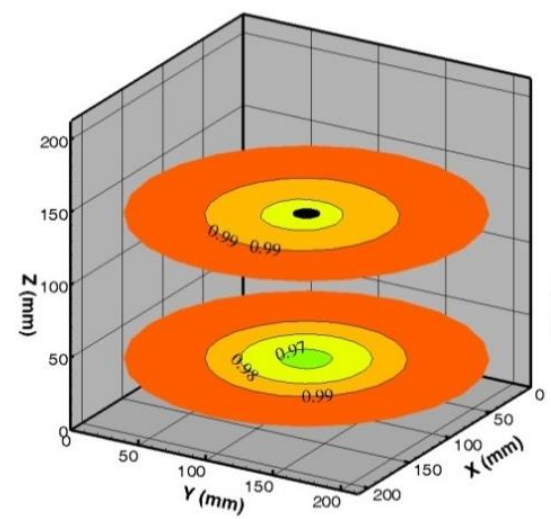

(a)

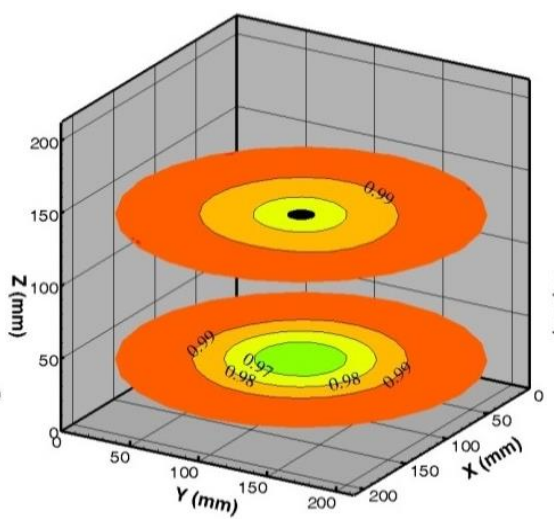

(b)

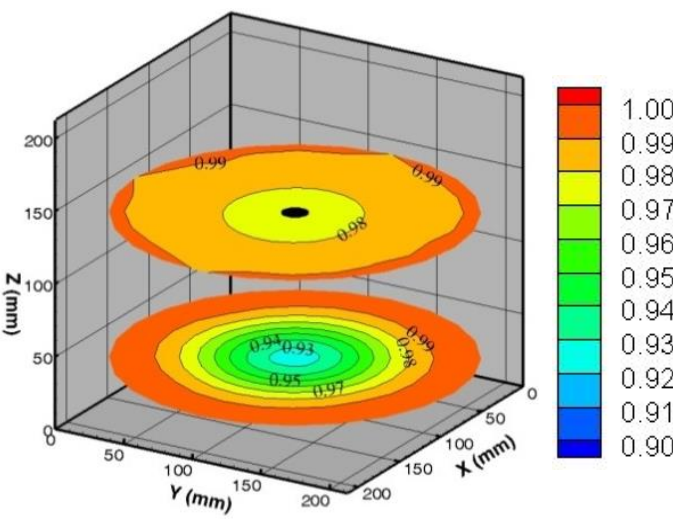

(c)

Figure 6. Dimensionless conductivity, PBTU. $\mathrm{Q}_{\mathrm{G}}=2 \mathrm{vvm}$. (a) $\mathrm{N}=100 \mathrm{rpm}$ (b) $\mathrm{N}=300 \mathrm{rpm}$ (c) $\mathrm{N}=500$ rpm.

A comparison among the different gas dispersions obtained with the three impellers under the same operating conditions (same $\mathrm{N}$ and $\mathrm{Q}_{\mathrm{G}}$ ) can be obtained from the observation of Figures 3, 5 and 6. For a comprehensive evaluation of the different impellers, further important parameters, such as the power consumption, should be considered, while fixing same impeller speed and gas flow rate conditions. 
The gas distribution is markedly more uniform with the PBTU than with the A310, particularly on the upper plane and the higher impeller speed (Figure $6 \mathrm{c}$ ); besides, less marked differences can be appreciated comparing Figure 5a with Figure 6a and Figure 5b with Figure 6b.

The profiles of gas distribution along the vessel radius measured with the RT are shown in Figure 7, for providing detailed information on the local variation of gas distribution for the flooding, large cavities and completely dispersed regimes on the upper (Figure 7 a) and the lower (Figure 7 b) measurement planes. The results show the parameter $\varepsilon$ defined above, which provides a picture of the gas distribution without giving a quantitative map of the hold-up. The overall gas hold-up, as calculated with the correlation proposed by Paglianti et al. [44] for the completely dispersed condition, is equal $1.6 \%$, while for the large cavity regime it rises at $4.4 \%$. The local $\varepsilon$ values, as compared with the predicted overall gas hold-up, are reasonable, also considering that the experimental data are relevant to two vessel planes only, while the correlation provides the integral hold-up on the whole vessel volume.

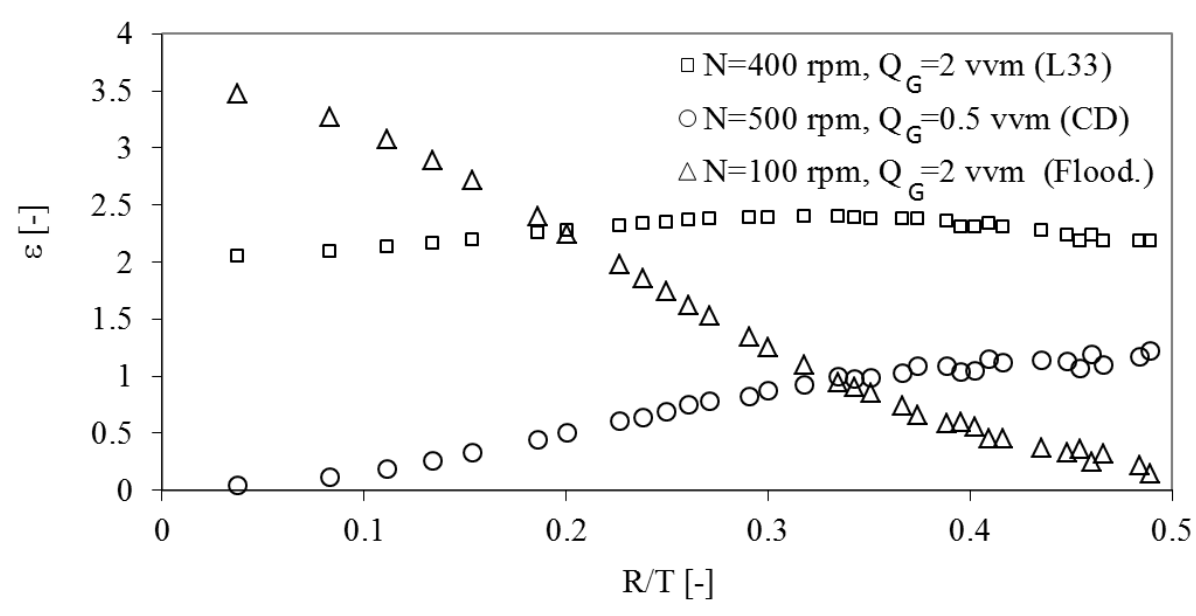

(a)

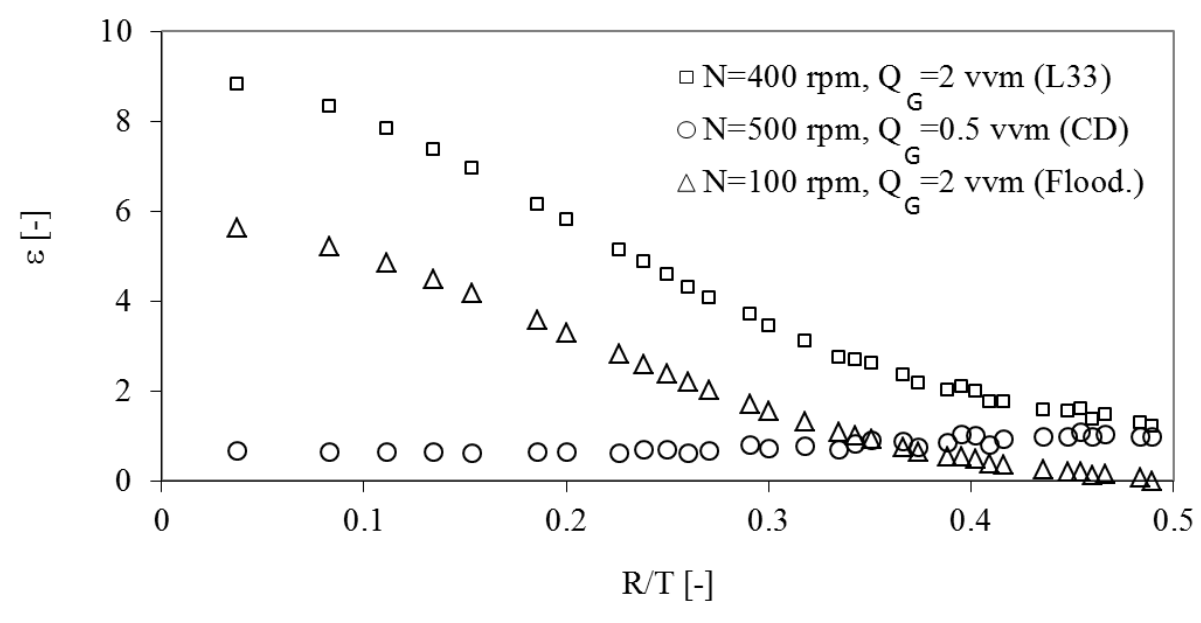

(b)

Figure 7. Radial profiles of gas distribution. (a) $\mathrm{z}_{2}=140 \mathrm{~mm}$; (b) $\mathrm{z}_{1}=40 \mathrm{~mm}$. 
The gas accumulation in the central region of the vessel, that is measured on both the planes under the flooded conditions, is limited to the lower plane in the L33 regime, while the gas homogeneity is apparent in the completely dispersed regimes. These results may provide a strict benchmark for CFD models of gas-liquid stirred tanks, which validation is often limited by the lack of local experimental data.

\subsection{The liquid mixing time under ungassed and aerated conditions}

The typical tracer homogenization dynamic curves obtained on the two measurements planes as the average dimensionless conductivity are shown in Figure 8, as an example of the typical outcome of the tracer injection experiments performed for the liquid mixing time determination. As can be observed, the dynamics tracer concentration on the two planes is significantly different. Above the impeller $\left(\mathrm{z}_{2}=140 \mathrm{~mm}\right)$, the mean conductivity increases with time until the complete homogenization is achieved. Instead, the time trace recorded below the impeller $\left(\mathrm{z}_{1}=40 \mathrm{~mm}\right)$, that is close the injection point located at $\mathrm{z}=62 \mathrm{~mm}$, exhibits a peak at five seconds from the injection, since the concentrated salt solution reaches it soon after its entrance. Thus, just for a short time interval after the injection, the conductivity on the plane is much higher than the steady state value, due to the relative position of the injection point and of the measurement plane.

As expected, this behaviour is similar to that observed during the homogenization of two miscible fluids [31]. With respect to the method adopted by Wang et al., [22] for the analysis of the mixing dynamics in gas-liquid systems, where a single point time trace was considered, the curves presented in this work are obtained as the mean conductivity value on the overall cross section. Although the curves shape depends on the position, the comparison of the calculated t95 on the two planes confirms that generally the time to achieve the fixed $95 \%$ homogeneity level is not significantly different at the various elevations [28]. 


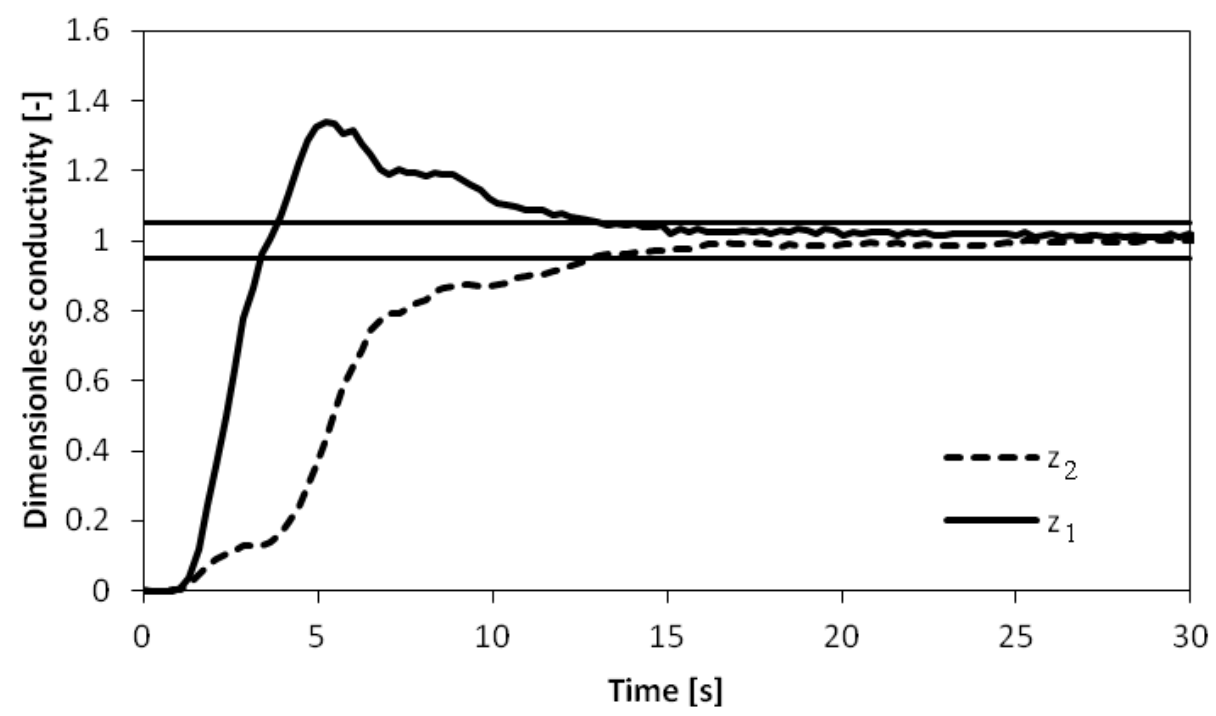

Figure 8. Time trace of the dimensionless mean conductivity on the two measurement planes.

The mixing time estimated at different gas flow rates and impeller speeds with the RT is shown in Figure 9. A preliminary assessment of the technique accuracy was performed by comparing the t $_{95}$ measured in ungassed conditions and the predictions of a well established literature correlation [45] and a close agreement was found. As can be observed, although the extent of mixing time variations with the gas flow rate largely depends on the impeller speed, it is definitely shorter in gassed than in ungassed conditions, as far as the impeller speed is relatively small; increasing the impeller speed, the relative position between the mixing time measured for ungassed and gassed conditions is reversed. A critical value of $\mathrm{N}$ is identified between 300rpm and 400rpm, which discriminates between the two behaviours. This effect is most liked due to the dramatic difference on the overall fluid circulation inside the tank depending on the impeller speed. The non-monotonic dependency of $t_{95}$ on the gas flow rate at fixed impeller speed, that is marked at $100 \mathrm{rpm}$, may well be due to the complex fluid dynamics occurring when the impeller is flooded.

The increase of the mixing time above a critical impeller speed under sparged conditions is in general agreement with previous findings [6,21] based on results collected with different techniques. Moreover, Pandit and Joshi [46] suggested a criterion for the evaluation of this critical impeller speed, which for the stirred tank adopted in this work leads to the estimate of $370 \mathrm{rpm}$. This value agrees with the experimental trend shown in Figure 9. 


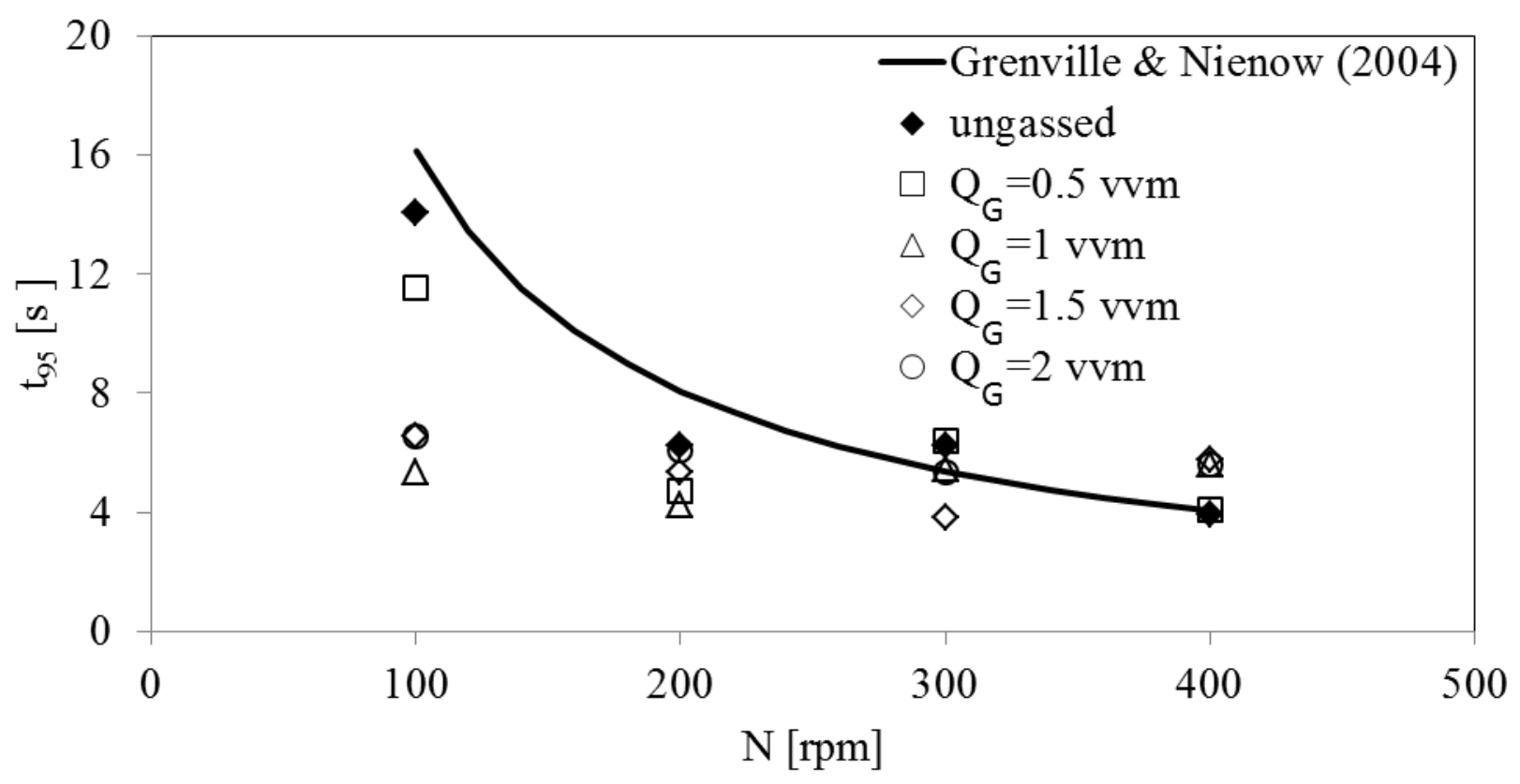

Figure 9. Dependency of t95 $_{5}$ on gas flow rate and impeller speed. RT

\subsection{Identification of the gas flow regimes based on the coefficient of variation of the local conductivity}

Based on the measured local conductivity, a quantitative analysis aimed at objectively identifying the gas flow regimes taking place in the vessel stirred with the three investigated impellers under the different operating conditions is proposed in the following. The known transitions between the various flow regimes determined in the past for the Rushton turbine as a function of the dimensionless gas flow number, Fl, and the impeller Froude number, Fr, have been considered as a reference. The flow regimes have been assessed comparing the mixing index, MI, evaluated at the measurement plane, $\mathrm{j}$, as:

$M I_{j}=\frac{1}{\bar{\sigma}} \sqrt{\frac{\sum_{i=\mathbf{1}}^{q}\left(\sigma_{i}-\bar{\sigma}\right)^{2}}{q-1}}$

where $\sigma_{i}$ is the dimensionless conductivity of the pixel i, $\bar{\sigma}$ is the dimensionless mean conductivity on the plane and $\mathrm{q}$ is the number of pixel in each plane. Finally, the parameter $\mathrm{S}$ has been estimated as:

$S=\frac{1}{\overline{M I}} \sqrt{\sum_{i=1}^{2}\left(M I_{i}-\overline{M I}\right)^{2}}$

The MI values and the corresponding S parameter relevant to the measurements shown in Figures 3, 5 and 6 are shown in Table 2, for a quantitative evaluation of the effect of the flow regime on the gas dispersion quality. 


\begin{tabular}{|c|c|c|c|c|c|c|c|}
\hline Figure & Impeller & $\mathrm{N}$ [rpm] & $\mathrm{Q}_{\mathrm{G}}[\mathrm{vvm}]$ & Flow regime & $\mathrm{MI}_{\mathrm{z} 1}[-]$ & $\mathrm{MI}_{\mathrm{z} 2}[-]$ & $\mathrm{S}[-]$ \\
\hline $3 a$ & Rushton & 100 & 2 & flooding & 0.0156 & 0.0095 & 0.34 \\
\hline $3 \mathrm{~b}$ & Rushton & 300 & 2 & flooding & 0.0229 & 0.0099 & 0.56 \\
\hline $3 \mathrm{c}$ & Rushton & 300 & 1.5 & L33 & 0.0216 & 0.0043 & 0.95 \\
\hline $3 \mathrm{~d}$ & Rushton & 500 & 2 & S33 & 0.0145 & 0.0043 & 0.76 \\
\hline $3 \mathrm{e}$ & Rushton & 400 & 0.5 & $\mathrm{VC}$ & 0.0075 & 0.0022 & 0.77 \\
\hline $3 \mathrm{f}$ & Rushton & 500 & 0.5 & $\begin{array}{c}\text { completely } \\
\text { dispersed }\end{array}$ & 0.0025 & 0.0035 & 0.22 \\
\hline $5 \mathrm{a}$ & A 310 & 100 & 2 & flooding & 0.0109 & 0.0083 & 0.19 \\
\hline $5 \mathrm{~b}$ & A310 & 300 & 2 & flooding & 0.0210 & 0.0098 & 0.51 \\
\hline $5 \mathrm{c}$ & $\mathrm{A} 310$ & 500 & 2 & loading & 0.0305 & 0.0094 & 0.75 \\
\hline $6 \mathrm{a}$ & PBTU & 100 & 2 & flooding & 0.0088 & 0.0061 & 0.25 \\
\hline $6 \mathrm{~b}$ & PBTU & 300 & 2 & flooding & 0.0106 & 0.0064 & 0.34 \\
\hline $6 \mathrm{c}$ & PBTU & 500 & 2 & loading & 0.0205 & 0.0046 & 0.90 \\
\hline
\end{tabular}

Table 2. MI and S values for selected conditions, as in Figures 3 (RT), 5 (A310) and 6 (PBTU).

All the results of the calculations for the RT are represented in Figure 10 on the flow map firstly proposed by Smith and co-workers [5], which allows the prediction of hydrodynamics in gas-liquid tanks stirred by RT. The lines defining the boundary between the regimes, are drawn based on the correlation of Smith and co-workers and Nienow and co-workers, as summarized by Bombac et al. [13].

In the following, the expected values of $\mathrm{S}$ as a function of the flow regime of the RT are discussed, in order to demonstrate that the actual gas dispersion can be identified by a simple analysis of the proposed index. When the impeller is flooded, the gas phase rises toward the vessel top being located just in the vessel central region and the gas distribution above and below the impeller is almost the same, therefore the expected $\mathrm{S}$ value is low. Moving towards the dispersed regime, either by increasing the impeller speed or by decreasing the gas flow rate, significantly different values of the MI are obtained above and below the impeller, therefore the value of $\mathrm{S}$ increases. Finally, when the completely dispersed regime is approached, the MI on the two planes achieves similar values and the standard deviation decreases again. 


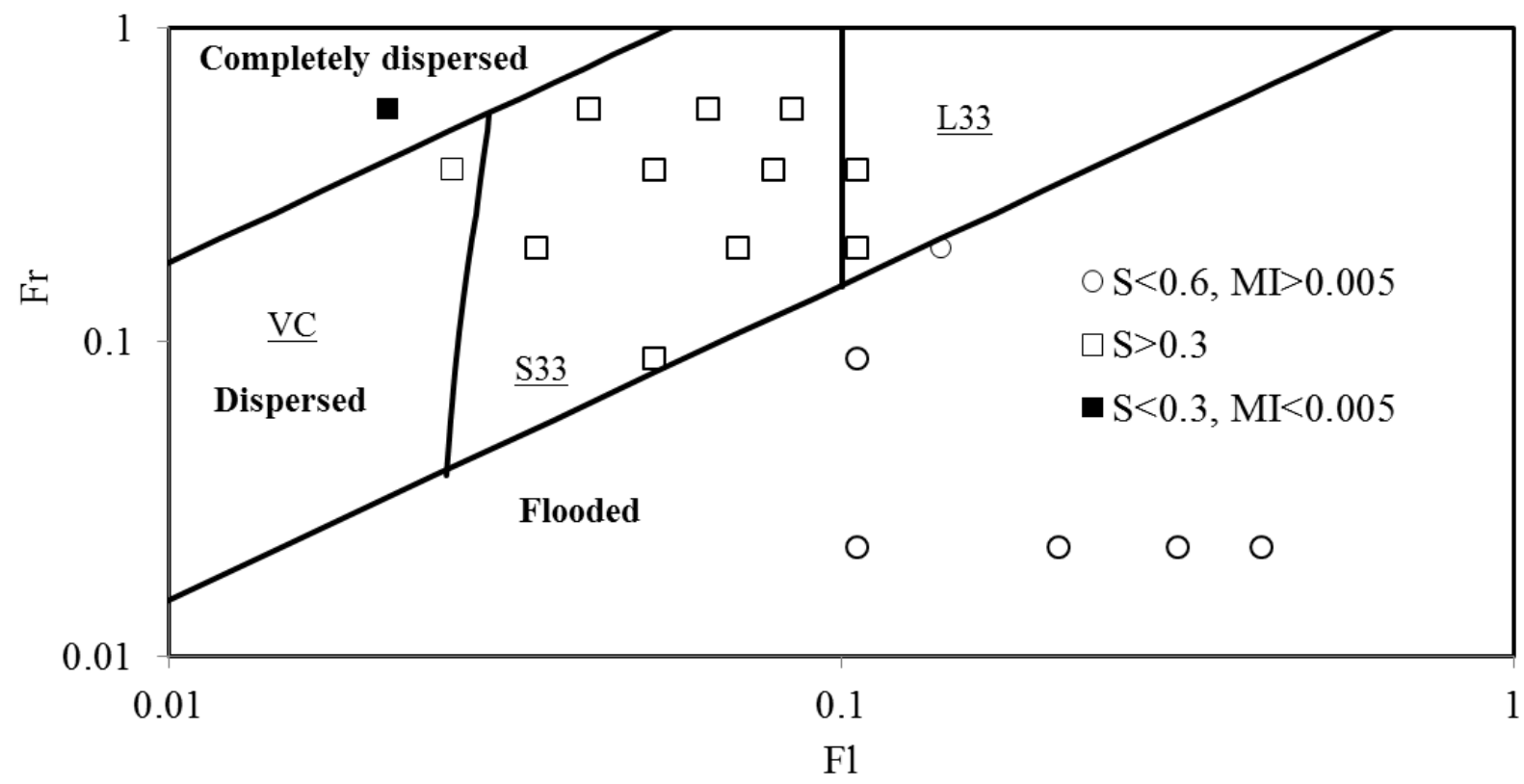

Figure 10. Flow map for the RT. Symbols: experimental values of S, lines: equations defining the transitions between the flow regimes.

The $\mathrm{S}$ index provides an objective method for the assessment of the behaviour qualitatively observed in previous works [e.g. 36]. Based on these considerations, it is reasonable to expect that two $\mathrm{S}$ threshold values would be sufficient for identifying the flow regime of any gas-liquid stirred tank on a quantitative basis. It is worth specifying that although low values of $\mathrm{S}$ are expected for both the flooded and the fully dispersed regimes, the two conditions can be easily discriminated considering the MI value above the impeller, that is much higher when the impeller is flooded than for the fully dispersed regime. Finally, the sum of the two MIs are different for L33, S33 and VC regimes, due to the different capability of the impeller of distributing the gas phase on the two planes. Comparing our results with the map reported by Bombac et al. [13], the transition L33-S33 is identified at the sum of MIs equal to 0.024 , while the S33-VC transition is at a value of 0.01 . The data collected for the RT summarized in Figure 10 show that for all the flooding conditions, the $\mathrm{S}$ value is lower than 0.6 , while for the fully dispersed regime $\mathrm{S}$ is lower than 0.3 . Also, the MI value obtained for the upper plane in the fully dispersed regime is below the limit of 0.005 .

The threshold values of S identified in the case of RT can be usefully adopted for the assessment of the prevailing regime taking place in the reactor stirred with different impellers, which have been less extensively investigated for gas-liquid dispersions.

The following linear relationship has been adopted for the identification of the flooding/loading condition also for the A310 and the PBTU cases: 
Where $c$, which has been identified based on the $S$ threshold values of 0.6 , is equal to 7.6 and 4.5 for the A310 and the PBTU respectively. As a result, adopting the same representation of Figure 10, the estimated $\mathrm{S}$ value corresponding to the different operating conditions considered with the axial and the mixed-flow impellers have been plotted in Figure 11 and 12 respectively.

Since mixing in stirred tanks can be required for different tasks simultaneously and mixed flow or purely axial impellers can be well adopted for gas dispersion, the definition of a quantitative and simple criterion for assessing the gas dispersion regime may be a guideline for the selection of operating conditions assuring sufficient gas distribution.

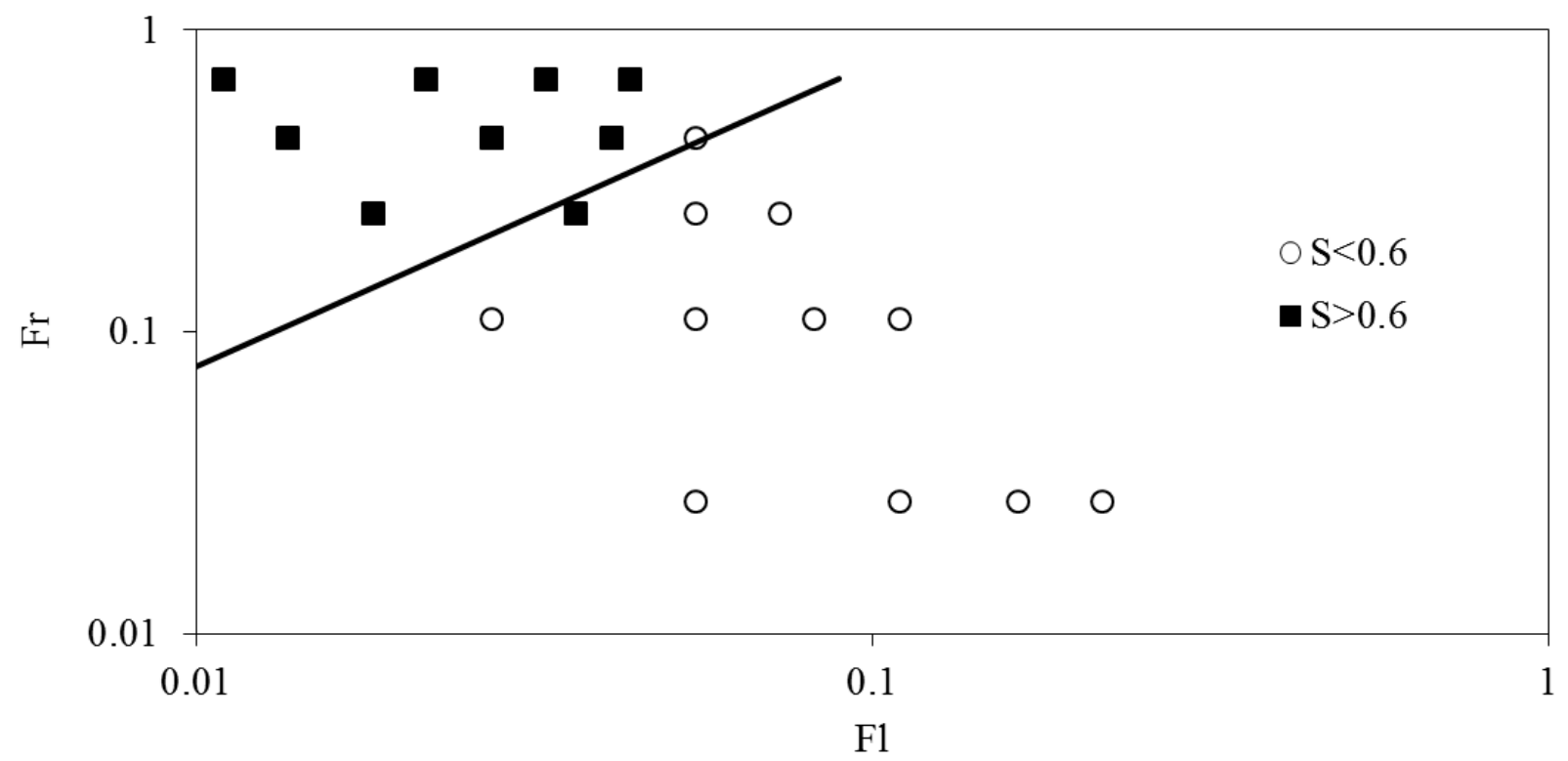

Figure 11. Flow map for the A310. Symbols: experimental values of S, line: Equation (3) defining the transitions between flooding and loading. 


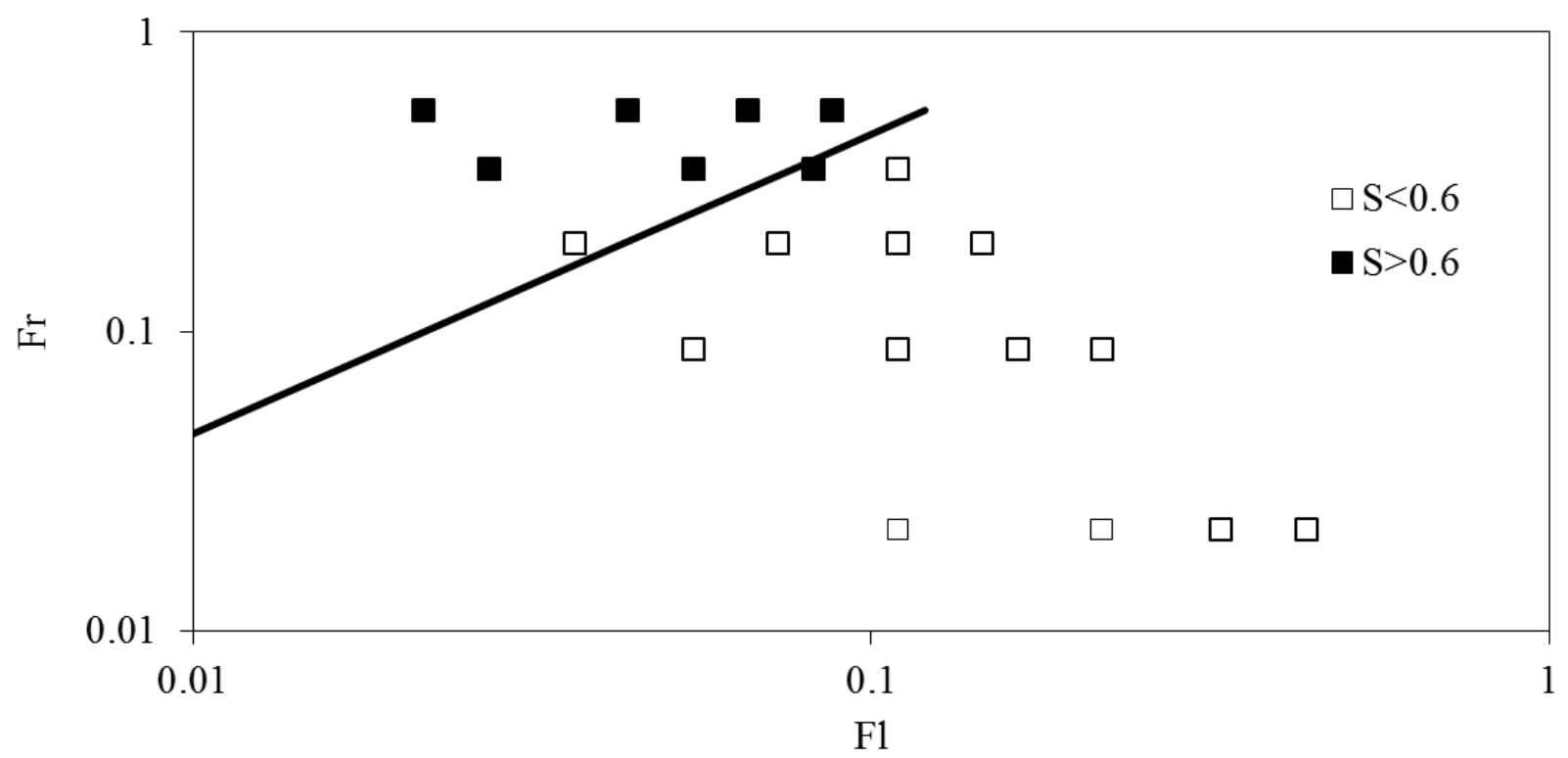

Figure 12. Flow map for the PBTU. Symbols: experimental values of S, line: Equation (3), defining the transitions between flooding and loading.

\subsection{A simplified approach to evaluate the gas dispersion and the mixing time}

The capability of the impeller to distribute the gas phase throughout the entire vessel at fixed impeller speed and gas flow rate has been further analysed by extending to the gas-liquid systems an approach recently proposed for predicting the mixing quality of a solid-liquid stirred tank by Carletti et al. [47].

In this work, the ratio of the MI values at the flooding and at any generic condition has been related to a modified Peclet number, $\mathrm{Pe}^{*}$, defined as:

$P e^{*}=\frac{\mathbf{U}_{b} H_{L}}{D_{e r}}$

Where $\mathrm{U}_{\mathrm{b}}$ is the bubble rise velocity and $\mathrm{D}_{\mathrm{er}}$ is a relative axial dispersion coefficient:

$D_{e r}=a\left(N-N_{f l}\right) D^{2}$

with $a$ being a dimensional constant, equal to 0.15 for the A310, 0.12 for the PBTU and 0.16 for the Rushton turbine [48] and $\mathrm{N}_{\mathrm{fl}}$ the impeller speed at the flooding condition. The bubble rise velocity has been assumed equal to $0.12 \mathrm{~m} / \mathrm{s}$, based on previous experimental data relevant to a similar system [10]. 
The dimensionless overall MI, that is the standard deviation from the mean conductivity value of the whole measurement area (including the two planes), are shown as a function of 1/Pe* in Figure 13. As can be observed, in all cases, below $\mathrm{N}_{\mathrm{fl}}$, that is for negative values of the abscissa, the increase of impeller speed provokes the increase of MI ratio, since major gas distribution differences are obtained between the two planes. Above the flooding point, for the radial RT at increasing impeller speed the MI decreases, and therefore the ratio $\mathrm{MI}_{\mathrm{MI}} \mathrm{MI}_{\mathrm{fl}}$ decreases, as expected since increasing the impeller speed above the flooding point a better gas dispersion is obtained. On the contrary, with down-pumping A310 impeller a different trend is observed: the increase of the impeller speed above the flooding point gives rise to an increase of the MI. This behaviour is probably due to the accumulation of gas-phase below the impeller plane occurring when the regime changes from direct impeller loading to the indirect impeller loading. As for the PBTU, just a few conditions above the flooding points have been investigated due to experimental limitations; therefore, firm conclusions cannot be drawn, although an increasing trend, similar to the RT, is visible.

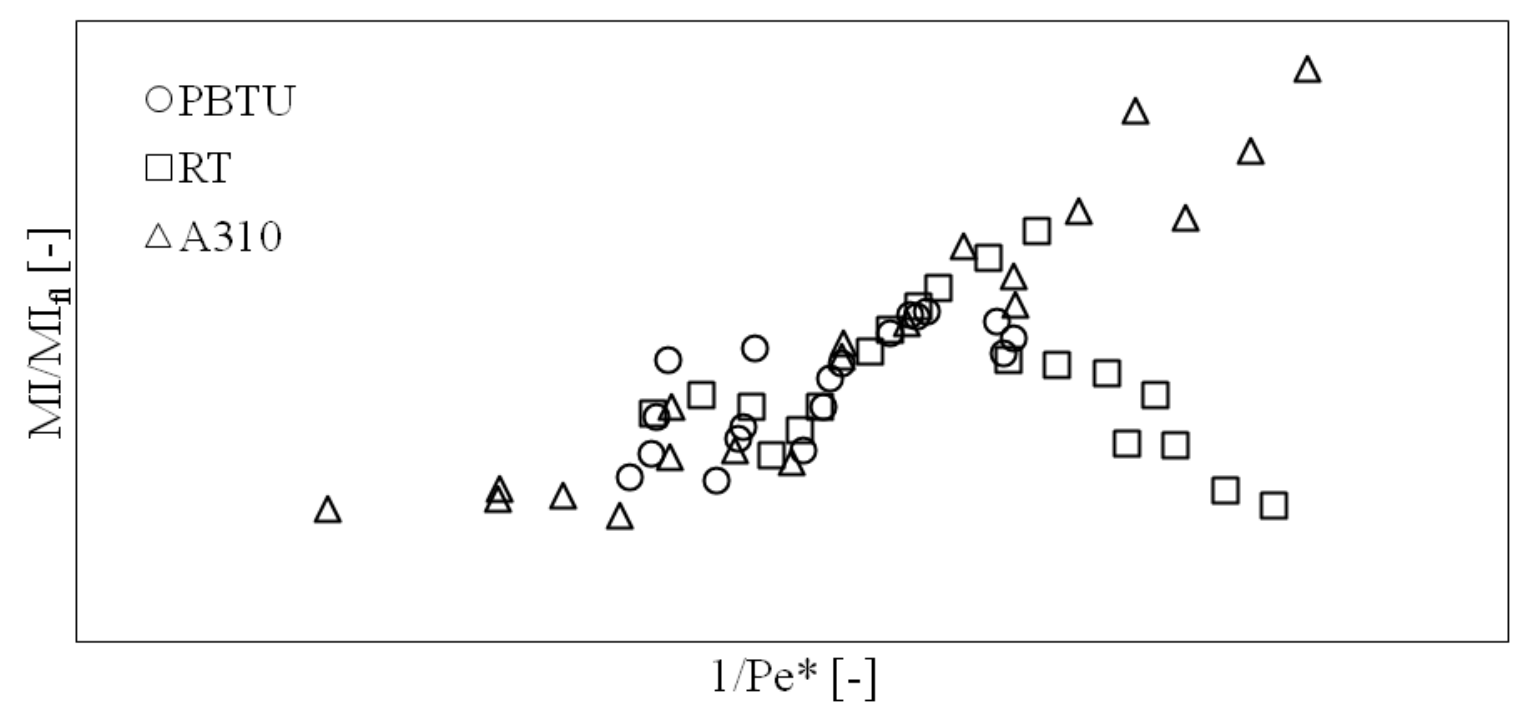

Figure 13. Dependency of the MI ratio on the modified Peclet number for different impellers.

The dependency of the mixing time from the same dimensionless parameter is shown in Figure 14. In particular, the ratio of the dimensionless mixing time, $\theta$, that is $t_{95} \times \mathrm{N}$, measured at various $\mathrm{N}$ up to $400 \mathrm{rpm}$ and at the flooding point shows different trends depending on the impeller type. As for the RT and the A310, an almost linear trend can be observed, because above the flooding condition, the mixing time variations with $\mathrm{N}$ are slight (for the RT, see the experimental data shown in Figure 
9) and therefore $\theta$ results linearly dependent on $N$. The deviation from the linear trend at specific $1 / \mathrm{Pe}^{*}$ values may well be due to flow regime variations, which are not taken into account by the proposed simplified approach. For instance, at $1 / \mathrm{Pe}^{*}=0.05$ the $\mathrm{RT}$ datum exhibits a drop, which may be associated to the transition from dispersed to completely dispersed condition. As for the PBTU, although firm conclusions cannot be drawn due based on the limited data collected particularly in the loading regime, a different behaviour is observed, since the mixing time decreases significantly with $\mathrm{N}$ above the flooding condition. In order to interpret this result, it is worth observing that the gas distribution and consequently the fluid dynamics in the flooding and loading conditions are completely different (see Figure $6 \mathrm{~b}$ and $6 \mathrm{c}$ ).

The position of the tracer injection might be also investigated, in order to confirm the observed dependency on the $\mathrm{Pe}^{*}$.

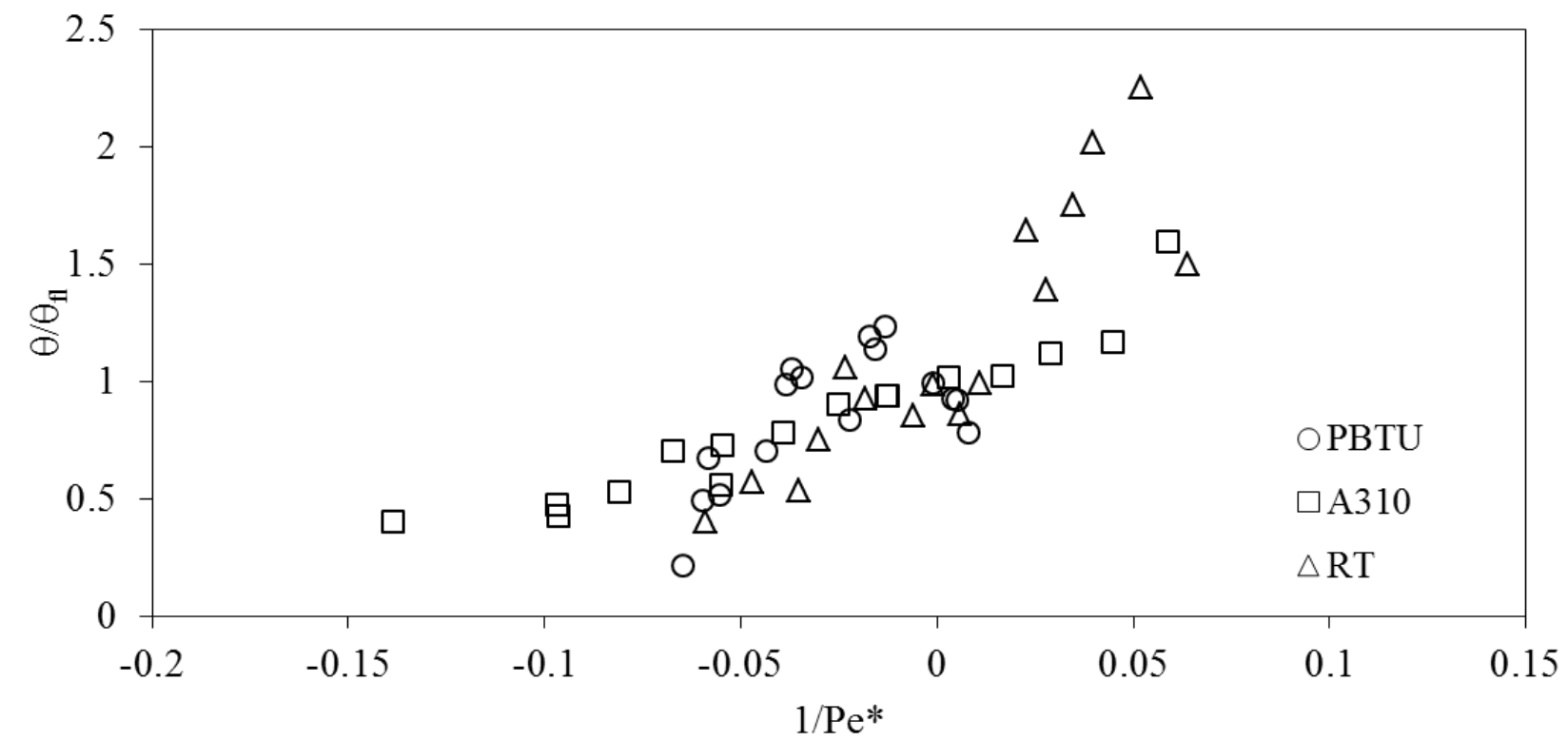

Figure 14. Dependency of the normalized dimensionless mixing time on the modified Peclet number for different impellers.

A dependency on $1 / \mathrm{Pe}^{*}$ is clearly found with all the impellers for the ratio between $\varepsilon$ and $\varepsilon_{\mathrm{fl}}$, as shown in Figure 15. The increase of the mean void fraction going from the flooding to the loading conditions is apparent, while, in the flooding conditions and far from the flooding point, an asymptotic value of the ratio $\varepsilon / \varepsilon_{\mathrm{fl}}$ is approached. 


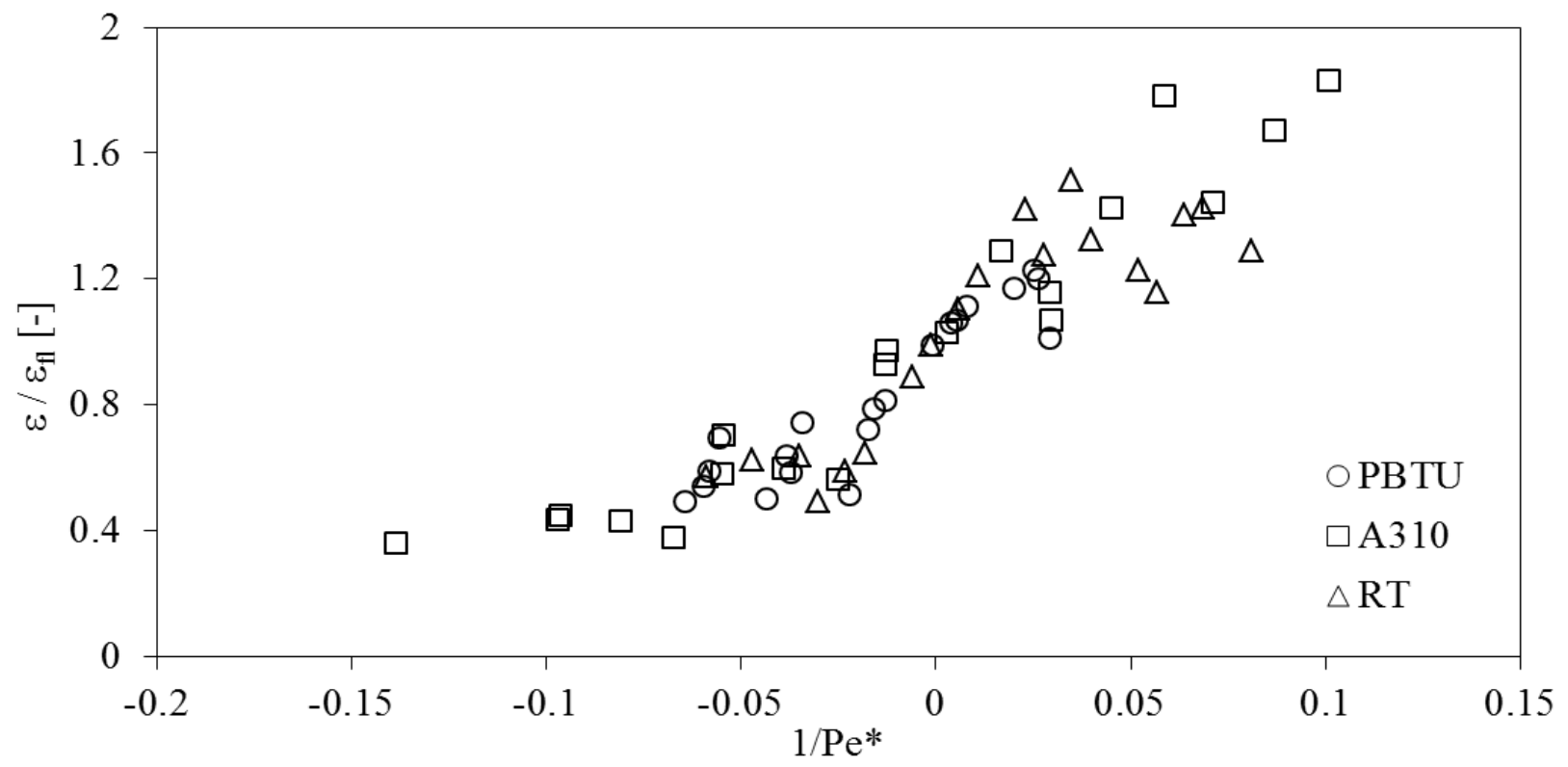

Figure 15.Dependency of the dimensionless $\varepsilon$ on the modified Peclet number for different impellers.

Overall, the modified Peclet number appears to be a suitable parameter for the description of the global behaviour of gas-liquid stirred tanks, although further investigation an a wider set of conditions is required for a deeper assessment. In particular, since the applicability of the proposed approach has been tested for one vessel size only, additional data on different tank sizes would allow to verify the scale-up effect on the dimensionless parameters' dependency.

\section{CONCLUSIONS}

The ERT measurements of gas distribution and liquid mixing time in a sparged stirred tank have allowed a local characterization of the two-phase system under different geometrical and operating conditions, including high overall gas hold-up, that is of scientific and industrial relevance, being the stirred chemical and biochemical reactors often operated under intense aeration condition. The flow regimes arising from the gas-impeller interactions under variable impeller speeds and gas flow rates have been associated to local measurements of conductivity distribution, thus allowing to move from a qualitative picture to a quantitative analysis based on the definition of global indexes calculated from local quantities. From the analysis, simple guidelines have been obtained for the prediction of the prevailing flow regimes based on the dimensionless Froude and Flow numbers.

Finally, a simplified approach for the evaluation of the mixing time and the mean gas void fraction, as a function of the modified Peclet number, has been identified, which holds true for all the investigated impellers. On the contrary, for the quality of the gas distribution mixing index a unified approach, independent from the impeller type, cannot be identified. Above the impeller plane, with 
radial and up-pumping impellers the mixing effectiveness increases with the impeller speed, while for down-pumping impellers the reversed effect is obtained, due to the accumulation of bubbles below the impeller.

\section{Acknowledgment}

This work has been carried out by the financial support of the University of Bologna and the Italian Ministry of University and Research (MIUR) under the project SO.FI.A -CTN01_00230_450760. The collaboration of Mr Luigi Da Vià in carrying out part of the experimental program and the valuable advices of Prof. Franco Magelli are gratefully acknowledged.

\section{Nomenclature}

C clearance, $\mathrm{m}$

D impeller diameter, $\mathrm{m}$

$\mathrm{D}_{\mathrm{er}} \quad$ relative axial dispersion coefficient, $\mathrm{m}^{2} \mathrm{~s}^{-1}$

Fl Flow number, $\left(F l=Q_{\downarrow} G /\left(N D^{\top} 3\right)\right)$, dimensionless

Fr Froude number, $\left(F r=\frac{N^{2} D}{g}\right)$, dimensionless

g gravity acceleration, $\mathrm{m} \mathrm{s}^{-2}$

$\mathrm{H} \quad$ vessel height, $\mathrm{m}$

$\mathrm{H}_{\mathrm{L}} \quad$ liquid height, $\mathrm{m}$

MI mixing index, dimensionless

$\overline{M I}$

mean mixing index, dimensionless

$\mathrm{N} \quad$ impeller speed, $\mathrm{s}^{-1}$

$\mathrm{N}_{\mathrm{fl}} \quad$ impeller speed at flooding, $\mathrm{s}^{-1}$

$\mathrm{Pe}^{*} \quad$ modified Peclet number, dimensionless

$\mathrm{Q}_{\mathrm{G}} \quad$ gas flow rate, $\mathrm{m}^{3} / \mathrm{s}$

q number of measurement planes

$\operatorname{Re} \quad$ impeller Reynolds number $\left({ }^{R e}=\frac{\rho N^{2} D}{\mu}\right)$, dimensionless

T vessel diameter, $\mathrm{m}$

$\mathrm{U}_{\mathrm{b}} \quad$ bubble rise velocity, $\mathrm{m} \mathrm{s}^{-1}$

t95 mixing time, $\mathrm{s}^{-1}$

$\mathrm{z} \quad$ axial coordinate, $\mathrm{m}$ 


\section{Greek letters}

$\varepsilon$

parameter proportional to the gas hold-up, dimensionless

$\rho \quad$ liquid density, $\mathrm{kg} \mathrm{m}^{-3}$

$\mu \quad$ liquid viscosity, $\mathrm{Pa} \mathrm{s}$

$\sigma \quad$ dimensionless conductivity

$\sigma_{\mathrm{i}} \quad$ dimensionless conductivity of pixel i

$\bar{\sigma} \quad$ mean dimensionless conductivity

$\theta \quad$ dimensionless time

Abbreviations

CFD Computational Fluid Dynamics

ERT Electrical Resistance Tomography

L33 large cavities

PBTU up-pumping 6-bladed Pitched Blade Turbine

RT Rushton Turbine

S33 small cavities

VC vortex clinging cavities

\section{Subscripts}

fl flooding point

1 lower measurement plane

2 upper measurement plane

g gas phase

\section{References}

[1] Middleton J.C., Smith J.M., 2004. Gas-liquid mixing in turbulent systems. Chapter 11 in "Handbook of Industrial Mixing: Science and Practice" (Paul, E.L., Atiemo-Obeng, V.A., Kresta, S.M., Eds), Wiley-Interscience: Hoboken, NJ, pp599-604.

[2] Nienow, A.W., 1998. Hydrodynamics of stirred bioreactors. Appl. Mech. Rev., 51, 3-32.

[3] Vrábel, P., Van Der Lans, R.G.J.M., Luyben, K.Ch.A.M., Boon, L., Nienow, A.W., 2000. Mixing in large-scale vessels stirred with multiple radial or radial and axial up-pumping impellers: Modelling and measurements. Chem. Eng. Sci., 55, 5881-5896.

[4] Smith, J.M. (1991). Simple performances correlations for agitated vessels. Proc. of 7th European Congress on Mixing. Eds Bruxelmane M., Froment G., Brugge 18-20 Sept., p. 233241. 
[5] Warmoeskerken, M.M.C.G., Smith, J.M., 1985. Flooding of disc turbines in gas-liquid dispersions: A new description of the phenomenon. Chem. Eng. Sci., 40, 2063-2071.

[6] Vasconcelos, J.M.T., Alves, S.S., Nienow, A.W., Bujalski, W., 1998. Scale-up of mixing in gassed multi-turbine agitated vessels. Can. J. Chem. Eng., 76, 398-404.

[7] Guillard, F., Trägårdh, C., 2003. Mixing in industrial Rushton turbine-agitated reactors under aerated conditions. Chem. Eng. Process., 42, 373-386.

[8] Deen, N.G., Solberg, T., Hjertager, B.H., 2002. Flow generated by an aerated Rushton impeller: Two-phase PIV experiments and numerical simulations. Can. J. Chem. Eng., 80, 638-652.

[9] Aubin, J., Le Sauze, N., Bertrand, J., Fletcher, D.F., Xuereb, C., 2004. PIV measurements of flow in an aerated tank stirred by a down- and an up-pumping axial flow impeller. Exp. Therm Fluid Sci., 28, 447-456.

[10] Montante G., Paglianti A., Magelli F., 2007. Experimental analysis and computational modelling of gas-liquid stirred vessels. Chem. Eng. Res. Des., 85, 647-653.

[11] Montante, G., Horn, D., Paglianti, A., 2008. Gas-liquid flow and bubble size distribution in stirred tanks. Chem. Eng. Sci., 63, 2107-2118.

[12] Laakkonen, M., Honkanen, M., Saarenrinne, P., Aittamaa, J., 2005. Local bubble size distributions, gas-liquid interfacial areas and gas holdups in a stirred vessel with particle image Velocimetry. Chem. Eng. J., 109, pp. 37-47.

[13] Bombač, A., Žun, I., Filipič, B., Žumer, M., 1997. Gas-Filled Cavity Structures and Local Void Fraction Distribution in Aerated Stirred Vessel. AIChE J., 43, 2921-2931.

[14] Busciglio, A., Grisafi, F., Scargiali, F., Brucato, A., 2013. On the measurement of local gas hold-up, interfacial area and bubble size distribution in gas-liquid contactors via light sheet and image analysis: Imaging technique and experimental results. Chem. Eng. Sci., 102, 551566.

[15] Kong, L.-N., Li, W., Han, L.-C., Liu, Y.-J., Luo, H.-A., Al Dahhan, M., Dudukovic, M.P., 2012. On the measurement of gas holdup distribution near the region of impeller in a gasliquid stirred Rushton tank by means of $\gamma$-CT. Chem. Eng. J., 188, 191-198.

[16] Lee, B.W., Dudukovic, M.P., 2014. Determination of flow regime and gas holdup in gasliquid stirred tanks. Chem. Eng. Sci., 109, 264-275.

[17] Xie, M., Xia, J., Zhou, Z., Chu, J., Zhuang, Y., Zhang, S., 2014. Flow pattern, mixing, gas hold-up and mass transfer coefficient of triple-impeller configurations in stirred tank bioreactors. Ind. Eng. Chem. Res., 53, 5941-5953. 
[18] Bakker, A., Smith, J. M., Myers, K. J., 1994. How to disperse gases in liquids. Chemical Engineering (New York), 101, 98-104.

[19] Bakker, A., van den Akker, H.E.A., 1994. A computational model for the gas-liquid flow in stirred reactors. Chem. Eng. Res. Des., 72, 594-606.

[20] Khopkar, A.R., Rammohan, A.R., Ranade, V.V., Dudukovic, M.P., 2005. Gas-liquid flow generated by a Rushton turbine in stirred vessel: CARPT/CT measurements and CFD simulations. Chem. Eng. Sci., 60, 2215-2229.

[21] Paglianti, A., Pintus, S., 2001. An impedance probe for the measurements of liquid hold-up and mixing time in two/three-phase stirred tank reactors. Exp. Fluids, 31, 417-427.

[22] Wang, M., Dorward, A., Vlaev, D., Mann, R. 2000. Measurements of gas-liquid mixing in a stirred vessel using electrical resistance tomography (ERT). Chem. Eng. J., 77, 93-98.

[23] Abdullah, B., Dave, C., Nguyen, T.-H., Cooper, C.G., Adesina, A.A., 2011. Electrical resistance tomography-assisted analysis of dispersed phase hold-up in a gas-inducing mechanically stirred vessel. Chem. Eng. Sci., 66, 5648-5662.

[24] Sharifi, M., Young, B. 2013. Electrical resistance tomography (ERT) applications to chemical engineering. Chem. Eng. Res. Des., 91, 1625-1645.

[25] Zhao, D., Gao, Z., Müller-Steinhagen, H., Smith, J.M., 2001. Liquid-phase mixing times in sparged and boiling agitated reactors with high gas loading. Ind. Eng. Chem. Res., 40, pp. 1482-1487.

[26] Magelli, F., Montante, G., Pinelli, D., Paglianti, A. 2013. Mixing time in high aspect ratio vessels stirred with multiple impellers. Chem. Eng. Sci., 101, 712-720.

[27] Zhang, Q., Yang, C., Mao, Z.-S., Mu, J., 2012. Large eddy simulation of turbulent flow and mixing time in a gas-liquid stirred tank. Ind. Eng. Chem. Res., 51, 10124-10131.

[28] Pinelli, D., Bujalski, W., Nienow, A.W., Magelli, F., 2001. Comparison of experimental techniques for the measurement of mixing time in gas-liquid systems. Chem. Eng. Technol., 24, 919-923.

[29] Rodgers, T.L., Gangolf, L., Vannier, C., Parriaud, M., Cooke, M., 2011. Mixing times for process vessels with aspect ratios greater than one. Chem. Eng. Sci., 66, 2935-2944.

[30] Pakzad, L., Ein-Mozaffari, F., Upreti, S.R., Lohi, A., 2013. Evaluation of the mixing of nonNewtonian biopolymer solutions in the reactors equipped with the coaxial mixers through tomography and CFD. Chem. Eng. J., 215-216, 279-296.

[31] Kim, S., Nkaya, A.N., Dyakowski, T., 2006. Measurement of mixing of two miscible liquids in a stirred vessel with electrical resistance tomography. Int. Commun. Heat Mass Transfer, $33,1088-1095$ 
[32] Rodgers, T.L., Cooke, M., Siperstein, F.R., Kowalski, A., 2009. Mixing and dissolution times for a cowles disk agitator in large-scale emulsion preparation. Ind. Eng. Chem. Res., 48, 6859-6868.

[33] Hamood-ur-Rehman, M., Dahman, Y., Ein-Mozaffari, F., 2012. Investigation of mixing characteristics in a packed-bed external loop airlift bioreactor using tomography images. Chem. Eng. J., 213, 50-61.

[34] Hari-Prajitno, D., Mishra, V.P., Takenaka, K., Bujalski, W., Nienow, A.W., McKemmie, J., 1998. Gas-liquid mixing studies with multiple up- and down- pumping hydrofoil impellers: Power characteristics and mixing time. Can. J. Chem. Eng., 76, 1056-1068.

[35] Zhu, H., Nienow, A. W., Bujalski, W., Simmons, M.J.H., 2009. Mixing studies in a model aerated bioreactor equipped with an up- or a down-pumping 'Elephant Ear' agitator: Power, hold-up and aerated flow field measurements . Chem. Eng. Res. Des., 87, 307-317.

[36] Takriff, M.S., Hamzah, A.A., Kamarudin, S.K., Abdullah, J. 2009. Electrical resistance tomography investigation of gas dispersion in gas-liquid mixing in an agitated vessel. Journal of Applied Sciences. 9. 3110-3115.

[37] Takriff, M.S., Ahmad, A., Rosli, M.I., Jantan, S. 2013. ERT visualization of gas dispersion performance of aerofoil and radial impellers in an agitated vessel. Jurnal Teknologi (Sciences and Engineering), 64, 75-78.

[38] Alves, S.S., Maia, C.I., Vasconcelos, J.M.T., Serralheiro, A.J., 2002. Bubble size in aerated stirred tanks. Chem. Eng. J., 89, 109-117.

[39] Pinheiro, P.A.T., Loh, W.W., Wang, M., Mann, R., Waterfall, R.C., 1999. Threedimensional electrical resistance tomography in a stirred mixing vessel. Chem. Eng. Comm., $175,25-38$.

[40] Wilkinson, A.J., Randall, E.W., Long, T.M., Collins, A. 2006. The design of an ERT system for 3D data acquisition and a quantitative evaluation of its performance. Meas. Sci. Technol., 17, 2088-2096.

[41] Hosseini, S., Patel, D., Ein-Mozaffari, F., Mehrvar, M. 2010. Study of solid-liquid mixing in agitated tanks through electrical resistance tomography. Chem. Eng. Sci., 65, 1374-1384.

[42] Mann, R., 2005. Electrical process tomography: seeing "without eyes" inside stirred tank. J. Zhejiang Univ. Sci., 6A, 1379-1385.

[43] Assirelli, M., Bujalski, W., Eaglesham, A., Nienow, A.W. 2002. Study of micromixing in a stirred tank using a Rushton turbine: Comparison of feed positions and other mixing devices. Chem. Eng. Res. Des. 80, 855-863. 
[44] Paglianti, A., Takenaka, K., Bujalski, W., Takahashi, K. 2000. Estimation of gas hold-up in aerated vessels. Can. J. of Chem. Eng., 78, 386-392.

[45] Grenville, R.K., Nienow. A.W. 2004. Blending of Miscible Liquids. Chapter 9 in "Handbook of Industrial Mixing: Science and Practice" (Paul, E.L., Atiemo-Obeng, V.A., Kresta, S.M., Eds), Wiley-Interscience: Hoboken, NJ, pp. 509.

[46] Pandit, A.B., Joshi, J.B., 1983. Mixing in mechanically agitated gas-liquid contactors, bubble columns and modified bubble columns. Chem. Eng. Sci., 38 , 1189-1215.

[47] Carletti, C., Montante, G., Westerlund, T., Paglianti, A., 2014. Analysis of solid concentration distribution in dense solid-liquid stirred tanks by electrical resistance tomography. Chem. Eng. Sci., 119, 53-64.

[48] Pinelli D., Montante G., Magelli F., 2004. Dispersion coefficients and settling velocities of solids in slurry vessels stirred with different types of multiple impellers. Chem. Eng. Sci., 59, 3081-3089. 